\title{
MAPA DE COMPETITIVIDAD EN DISEÑO: VALIDACIÓN EN EMPRESAS DEL SECTOR LÁCTEO*
}

\author{
AIDA MANRIQUE LÓPEZ"* \& ADRIANA VARGAS ROJAS ${ }^{* * *}$ \\ UNIVERSIDAD DE BOGOTÁ JORGE TADEO LOZANO
}

Recibido/ Received/ Recebido: 13/07/2015-Aceptado/ Accepted/Aprovado: 20/06/2016

\begin{abstract}
Resumen
Este artículo integra el proceso, los resultados y las reflexiones de la investigación realizada con el propósito de identificar la situación y las perspectivas del diseño en algunas entidades públicas y privadas del sector lácteo, y explorar las formas de gestión utilizadas por un grupo de empresas de diferentes tamaños mediante el ajuste y la validación de una herramienta diagnóstica, en una muestra de 8 empresas productoras y comercializadoras de productos lácteos de Bogotá Región. Se exponen el marco conceptual y el proceso de actualización y validación de la herramienta Mapa de Competitividad en Diseño-MCD-, a partir de la teoría de las capacidades empresariales y los factores de competitividad determinantes del éxito empresarial. Los resultados permiten identificar las áreas o campos de actuación (producto, comunicación y entorno) y los niveles de integración (estrategia, política, programa y proyecto) del diseño en las empresas, y determinan tipologías según modelos de incorporación de la gestión del diseño en estas organizaciones. El trabajo realizado muestra la eficacia del Mapa de Competitividad en Diseño según Capacidades -MCDC-, resultante del ajuste, tanto para analizar los niveles de integración de la gestión de diseño desde los factores internos explicativos de la competitividad empresarial en las empresas, como para realizar análisis transversal de alcance sectorial.
\end{abstract}

Palabras clave: Diseño; Competitividad; Gestión de diseño; Recursos; Capacidades.

Artículo de investigación científica y tecnológica resultado del proyecto de investigación: "Situación y perspectiva del diseño en empresas productoras y comercializadoras de productos lácteos en la zona Bogotá-Región, 2014", que las autoras adelantaron en el marco de la convocatoria 10 de la Dirección de Investigación, Creación y Extensión, bajo la línea de investigación "Diseño, técnica, tecnología y gestión" de la Facultad de Artes y Diseño de la Universidad de Bogotá Jorge Tadeo Lozano.

Las autoras agradecen a los expertos de la Cadena Nacional Láctea -CNL-, Asoleche y del Programa de Transformación Productiva -PTP-, a los representantes de las 8 empresas de diferente tamaño que nos brindaron un espacio y tiempo para la realización de las entrevistas y la aplicación del MCDC, y a Patricia Paredes López por su asesoría en gestión de diseño. También agradecen a Jorge Del Castillo Delgado, director de la Especialización en Gerencia de Diseño de la Universidad Jorge Tadeo Lozano, por sus recomendaciones y apoyo durante todo el proyecto y por la revisión a la versión preliminar de este artículo.

* Diseñadora Industrial de la Universidad Nacional de Colombia, Especialista en Gerencia de Diseño de la Universidad de Bogotá Jorge Tadeo Lozano y Magíster en Estudios Culturales de la Pontificia Universidad Javeriana. Profesora asociada II de medio tiempo vinculada al Grupo de Investigación en Diseño, Pensamiento, Creación de la Facultad de Artes y Diseño de la Universidad de Bogotá Jorge Tadeo Lozano. Profesora asistente de medio tiempo vinculada al Grupo de Investigación en Gestión de Diseño del Departamento de Diseño de la Pontificia Universidad Javeriana. Dirección postal: Carrera 4 \# 22-61, Módulo 6 Piso 5, Oficina 54, Bogotá. Teléfono: (+57 1) 2427030 Ext. 1650 y 1652. Correo electrónico: aida.manrique@utadeo.edu.co

*.* Trabajadora Social de la Universidad Industrial de Santander, Especialista en Desarrollo Cultural de la Universidad Cooperativa de Colombia y Especialista en Gerencia de Diseño de la Universidad Jorge Tadeo Lozano. Vinculada al Grupo de Investigación en Gerencia de Diseño de la Facultad de Artes y Diseño, de la Universidad de Bogotá Jorge Tadeo Lozano. Correo electrónico: adriana. vargasr@utadeo.edu.co 


\title{
IN DESIGN COMPETITIVENESS MAP: DAIRY SECTOR COMPANIES VALIDATION
}

\begin{abstract}
This article integrates the process, the investigation's results and reflections that identifies the design's situation and prospects in some public and private entities in the dairy sector. It explores management methods used by a group of companies of different sizes by adjustment and validation of a diagnostic tool in a sample of 8 producing and marketing dairy companies in the Bogota Region. The conceptual framework and the in design competitiveness map -MCD- update and validation process are shown, from the theory of entrepreneurial skills and competitiveness factors that determine business success. The results allow to identify areas or fields of action (product, communication and environment) and levels of integration (strategy, policy, program and project) of design in the companies. They determine types according to incorporating models of design management in these organizations. The work shows the effectiveness of the Competitiveness Map In Design according to Capabilities -MCDC- resulting from the adjustment, both to analyze the levels of integration of design management from the explanatory internal factors of business competitiveness in the companies; and to make cross-sectoral scope analysis.
\end{abstract}

Keywords: Design; Competitiveness; Design management; Means; Capabilities.

\section{MAPA DE COMPETITIVIDADE EM DESENHO: VALIDAÇÃO EM EMPRESAS DO SETOR LÁCTEO}

\begin{abstract}
Resumo
Este artigo integra o processo, os resultados e as reflexões da pesquisa realizada com o propósito de identificar a situação e as perspectivas do desenho em algumas entidades públicas e privadas do setor lácteo, e explorar as formas de gerenciamento utilizadas por um grupo de empresas de diferentes tamanhos mediante o ajuste e a validação de uma ferramenta diagnóstica, em uma mostra de 8 empresas produtoras e comercializadoras de produtos lácteos de Bogotá Região. Expõem-se o marco conceitual e o processo de atualização e validação da ferramenta Mapa de Competitividade em Desenho -MCD-, a partir da teoria das capacidades empresariais e dos fatores de competitividade determinantes do sucesso empresarial. Os resultados permitem identificar as áreas ou campos de ação (produto, comunicação e contexto) e os níveis de integração (estratégia, política, programa e projeto) do desenho nas empresas, e determinam tipologias segundo modelos de incorporação do gerenciamento do desenho nestas organizações. O trabalho realizado mostra a eficácia do Mapa de Competitividade em Desenho segundo Capacidades -MCDC-, resultante do ajuste, tanto para analisar os níveis de integração do gerenciamento de desenho desde os fatores internos explicativos da competitividade empresarial nas empresas, como para realizar análise transversal de alcance setorial.
\end{abstract}

Palauras chave: Desenho; Competitividade; Gerenciamento de desenho; Recursos; Capacidades.

Manrique, A. \& Vargas, A. (2017). Mapa de competitividad en diseño: validación en empresas del sector lácteo. En: Revista de la Facultad de Ciencias Económica: Investigación y Reflexión. rev.fac.cienc.econ, XXV (1). DOI: http://dx.doi.org/10.18359/rfce.2659

JEL: M11, M19. 


\section{Introducción}

El diseño en la actualidad se reconoce como un factor clave para lograr ventajas competitivas, ya que permite desde su gestión integrar de forma sistemática los procesos de innovación y fortalecer la estrategia empresarial. En la sociedad contemporánea el auge y la expansión internacional del uso del diseño han permitido que se reconozca su papel en las estrategias de innovación de las empresas a partir de la integración de sus procesos, su organización y su gestión, trascendiendo las actividades centradas en la configuración de productos, empaques, envases y las comunicaciones visuales. En consecuencia, desde una gestión estratégica del diseño es posible potenciar los recursos y capacidades de la empresa para intervenir en mayor o menor grado en todas las actividades básicas del proceso de innovación: en la generación y desarrollo de nuevas estrategias, conceptos y productos, en la redefinición de procesos productivos y de comercialización, y en la gestión del conocimiento y de la tecnología (Montaña \& Moll, 2008, p. 65).

Se trata de un proceso creativo y estructurado enfocado a resolver de modo original problemas y limitaciones, no solo para crear productos, imágenes o espacios, sino también servicios, experiencias y, más aún, modelos de negocio completamente nuevos y estrategias empresariales innovadoras que apoyen el desarrollo de empresas e instituciones (Cotec, 2008, p. 11). Desde esta perspectiva es posible favorecer la competitividad empresarial a través de la integración del diseño desde enfoques estratégicos que permitan impulsar el desarrollo de propuestas que aborden enfoques innovadores.

Se convierte así el uso del diseño en una oportunidad para responder, desde el sector profesional y la academia, efectivamente a las potenciales demandas de las empresas que deben competir en un entorno dinámico y complejo, caracterizado por la presencia de consumidores críticos e influyentes que buscan productos diferenciados.

En el sector alimenticio se observa particularmente que las tendencias mundiales están marcadas por la presencia de un consumidor con un estilo de vida activo, preocupado por su salud, más informado, que demanda alimentos funcionales con beneficios para su salud, y que le brinden placer y facilidad de consumo. Para el caso específico del sector lácteo ${ }^{1}$ es posible ver, a nivel mundial, una creciente actividad en la generación de nuevos productos en las categorías de alimentos funcionales y nutraceúticos, que moviliza a la industria a desarrollar herramientas para un diseño más preciso de productos orientados a sectores específicos de la población. En Colombia, particularmente, las iniciativas del Programa de Transformación Productiva -PTP- del gobierno nacional y del Plan Regional de Competitividad de Bogotá y Cundinamarca (2010- 2019) bajo el «Modelo Empresarial de Gestión Agroindustrial" -MEGA-, buscan que el sector lácteo alcance altos estándares a través de planes públicos y de cooperación internacional dirigidos a fortalecer la producción local para contar con ganaderías más desarrolladas y con mayor conocimiento de la segmentación del mercado, innovación y la gestión comercial, para hacer frente a la posible entrada de productos internacionales, como consecuencia de los riesgos y oportunidades que plantean los diferentes tratados de libre comercio, suscritos con la Unión Europea, Estados Unidos, México, Chile y Mercosur -Argentina, Brasil y Uruguay-.

Todo lo anterior se hace considerando las preocupaciones derivadas de la balanza comercial negativa que ha reportado el país en este sector durante los últimos tres años, evidente en el 2013 con un registro de exportaciones de 35,1 millones de dólares frente a importaciones de 51,2 millones (DANE, 2015). Esta situación afecta las posibilidades de competitividad, productividad e innovación particularmente de las pequeñas y medianas empresas del sector, para afrontar con éxito las nuevas condiciones comerciales.

\footnotetext{
El sector lácteo comprende una actividad agrícola con la producción de leche cruda especializada o de ganado para doble propósito (leche y carne) como insumo básico a partir del cual se obtienen los productos lácteos, y también una actividad industrial con la fabricación de los diferentes productos como leche descremada, en polvo, azucarada, yogur, mantequilla, queso, helados y postres, entre otros.
} 
Pese a la importancia que tiene este sector para la economía colombiana ${ }^{2}$ y desde la documentación revisada, es posible afirmar que las estrategias formuladas para aumentar la competitividad de estos productos en el país, tienen un enfoque en aspectos técnicos, productivos, sanitarios y de calidad, y tienden a generar acciones orientadas a incrementar las actividades de innovación tecnológica como estrategia para hacer más competitivo este sector de la agroindustria, expuesto cada vez más a los retos y desafíos que impone la internacionalización de los mercados.

En el desarrollo de la investigación se realizó una exploración documental con el fin de detectar estudios de caracterización, específicos para el sector lácteo, con enfoque en diseño a partir de lo cual se constató la ausencia de información e indicadores en Colombia que evalúen de manera puntual el potencial del diseño y determinen estrategias integrales que lo utilicen para aumentar las ventajas competitivas de las empresas de este sector. A partir de la consulta de herramientas utilizadas en otros países, se encontraron algunos instrumentos para diagnosticar la situación del diseño en empresas de otros sectores diferentes al sector lácteo.

En España, se encontraron dos estudios. Uno enfocado en la identificación de la percepción de empresarios catalanes sobre el impacto del diseño en las empresas, realizado en el 2009 por el Centro de Diseño de Barcelona -BCD-, mediante un sondeo de opinión y mapas estratégicos; el segundo estudio, realizado por la Federación Española de Entidades de Promoción del Diseño, analiza el comportamiento en la gestión del diseño de la pequeña y mediana empresa española, y propone un modelo para gestionar el diseño en la empresa en empresas de los sectores de mobiliario, electrónico y turismo (Montaña \& Moll, 2008). En Chile se ubicó el pro-

2 El sector lácteo es de gran importancia para la economía colombiana por su participación en el PIB nacional que corresponde a cerca del 0,9\%, y del 9,7 \% del PIB agropecuario, su participación en la canasta familiar y el número de empleos que genera en la producción de leche (alrededor de 580.000) y en el procesamiento de productos lácteos (17.750), lo convierten en un sector destacado (Benchmark, 2015) yecto de investigación en diseño desde un sistema integrado de producción y mercado como factores básicos para incrementar la competitividad, de la Escuela de Diseño del Instituto Profesional Duoc UC (1997), en conjunto con la Compañía Tecno Industrial, el Centro Ricerche del Instituto Europeo Di Design y Design Innovation, ambos de Milán, Italia, a través de la Comisión Nacional de Investigación Científica y Tecnológica -CONICYT-. En Colombia se identifican: el estudio sobre los efectos de la intervención del diseño en las pymes de marroquinería y calzado (Paredes, Salazar \& Bautista, 2008), realizado por el grupo de investigación en gestión de diseño de la Pontificia Universidad Javeriana -PUJ-, durante el periodo 2005 a 2007, y el proyecto de investigación cualitativa sobre innovación por diseño en las Mipymes, desarrollado por el instituto de posgrados Forum de la Universidad de la Sabana y el Ministerio de Comercio, Industria y Turismo durante el 2010.

De acuerdo a lo encontrado en la exploración documental se planteó como objetivo general del proyecto verificar las posibilidades de uso de la herramienta diagnóstica especializada en gestión de diseño denominada Mapa de Competitividad en Diseño -MCD-, y luego ajustarla y validarla. Este ejercicio dio como resultado la generación de una nueva herramienta denominada Mapa de Competitividad en Diseño según Capacidades -MCDC-, la cual es útil para realizar una aproximación a la situación del diseño en algunas empresas enfocadas en la fabricación y comercialización de productos lácteos de Bogotá-Región. Se buscó con esto identificar los campos de actuación de la gestión del diseño desde los ámbitos operativo, táctico y estratégico, así como los niveles de integración (estrategia, política, programa y proyecto) y los modelos de incorporación de la gestión del diseño definidos a partir de 5 tipologías de empresas construidas por el equipo de investigación.

El proyecto tuvo una duración de un año y abordó 2 etapas: la primera en la que se hizo el reconocimiento de la situación general del sector en Colombia para identificar perspectivas sectoriales para el diseño, a través del análisis documental y la realización de entrevistas con expertos de la Cadena Nacional 
Láctea -CNL-, Asoleche y del Programa de Transformación Productiva -PTP-; y la segunda etapa relacionada con la identificación del estado actual del diseño en 8 empresas de diferente tamaño a través de la aplicación de la herramienta MCDC.

El cuerpo de este artículo se encuentra dividido en 3 partes: la primera aborda el marco conceptual sobre competitividad y diseño en el sector lácteo, la segunda integra los aspectos metodológicos con fases del proyecto que incluye un análisis de los niveles de integración de la gestión del diseño desde los factores internos explicativos de la competitividad empresarial y el comportamiento de la herramienta MCDC para la realización de un análisis transversal por factores de competitividad del grupo de $8 \mathrm{em}-$ presas estudiadas. Finalmente, la tercera parte expone los resultados, reflexiones y conclusiones del proyecto, y determina las perspectivas sectoriales para el diseño en el sector lácteo.

Entre las principales conclusiones y aportes de la investigación, se encuentra la contribución a la creación de conocimiento relacionado con la incidencia y las perspectivas del diseño en el sector lácteo, y las habilidades metodológicas de organizaciones interesadas en vincularlo desde un enfoque estratégico a través de una herramienta efectiva para el diagnóstico de su situación, a partir de factores internos del éxito empresarial que determinan su competitividad.

También se destaca el abordaje de ámbitos asociados específicamente al diseño, la competitividad y la gestión de diseño, para favorecer la generación de conocimiento y el desarrollo de instrumentos adecuados para vincularlo en organizaciones cada vez más competitivas.

\section{Marco conceptual}

En función de los objetivos del proyecto se formuló un marco conceptual desde el cual se aborda la competitividad empresarial y sus relaciones con la gestión del diseño, a partir del cual se diseñaron los instrumentos de diagnóstico estratégico que posibilitaron el acercamiento al sector y a las empresas estudiadas.
Para tal efecto se consultó la documentación existente sobre la situación actual del sector lácteo en el país, la política pública que lo respalda y promueve, así como la documentación existente sobre competitividad en empresas de diferentes sectores; en este último tema se consultaron estudios realizados en Colombia, España y México sobre pequeñas y medianas empresas. Así mismo, se revisaron los manuales de gestión de diseño disponibles y artículos nacionales e internacionales que plantean, especialmente en Europa, las posibilidades y retos que tiene el diseño, con el fin de explorar las posibles aplicaciones en el sector de alimentos y específicamente en el sector lácteos desde la gestión del diseño y sus aportes a la competitividad empresarial y el desarrollo de los países.

Una vez realizada la exploración y depuración de documentos, el análisis mostró que las diferencias en las formas de entender la competitividad y la innovación, y de citar el papel del diseño en relación con la competitividad de las empresas, hace necesario plantear una postura epistemológica que evidencie los antecedentes desde donde se están comprendiendo la competitividad, el diseño y su gestión en el sector lácteo.

\subsection{Diseño y competitividad}

Desde la década de los noventa en el país cambiaron los parámetros que determinan la competitividad de las empresas nacionales. Con el tránsito del modelo de industrialización por sustitución de importaciones al de apertura económica impulsado por el gobierno de César Gaviria Trujillo (1990-1994), la integración al mercado mundial ha exigido no solo producir y vender más barato, sino dotar a los productos de atributos que les añadan diferenciación.

Desde allí la noción de competitividad país - región - industria - empresa surge unida a los discursos de reconversión tecnológica y productividad, necesarios para la definición de sectores potencialmente exportadores y de estrategias de corto, mediano y largo plazo que permitieran generar un cambio en las estructuras productivas. El antecedente más significativo en el tema es el "Informe Monitor: Creación de la ventaja competitiva para Colombia" 
realizado por Michael Porter en 1994. Contratado por el Ministerio de Desarrollo Económico, el Instituto de Fomento Industrial, la Confederación Colombiana de Cámaras de Comercio y Bancoldex, este estudio evalúa los sectores de bienes de capital, flores, jugos de frutas, artes gráficas, petroquímicos, cuero y textiles para las seis principales ciudades: Bogotá, Medellín, Cali, Bucaramanga, Cartagena y Barranquilla.

El estudio señala la importancia de desarrollo de oportunidades de mercado para los productos colombianos en el exterior, eliminación de las barreras que le imponen sobrecostos a la producción doméstica y trabajo persistente en la utilización y dotación de mayor eficiencia a los factores productivos y el conocimiento de los mercados (CCB, 2013, párr. $1)$.

Es posible que derivado de esto las aproximaciones al concepto de competitividad empresarial de Porter hayan sido las que más impacto han tenido en las disciplinas económicas y administrativas del país desde la década de los noventa.

Cabrera et al. (2011, p. 23) exponen que:

Para Porter la competitividad es un indicador que mide la capacidad de una empresa de competir frente al mercado y a sus rivales comerciales. Alic (1987), la define como la capacidad de las empresas para diseñar, desarrollar, producir $y$ colocar sus productos en el mercado internacional en medio de la competencia con empresas de otros países. Urrutia (1994), afirma que es la capacidad de responder ventajosamente en los mercados internacionales. Reinel (2005), expone que es el performance valorado por la capacidad que tiene una empresa para generar más valor agregado que sus competidores. Román (2004), destaca la importancia de la innovación en la generación de productos.

Estos acercamientos tienen como criterios comunes aspectos técnicos, económicos y sociales centrados en el mercado (competencia y consumidores), la calidad de los productos ofrecidos, los bajos costos y la innovación (Bohórquez et al., 2012, p. 16). Así que la medición de este factor en lo empresarial, está asociado con indicadores de rentabilidad, productividad, exportaciones, innovación tecnológica, valor agregado, entre otros.

De igual forma, la perspectiva de análisis competitivo empresarial tradicional a la ciencia administrativa que establece como estrategias genéricas los costos, la diferenciación y la segmentación selectiva o enfoque, es la que más incidencia y relación ha tenido con el diseño (Porter, 1991). Esto dado que, ante una oferta amplia de productos, el diseño permite la diferenciación desde la introducción de valores simbólicos, prácticos y formales que justifican frente al consumidor un precio de venta correspondiente a valores agregados determinados por las necesidades y expectativas del mercado.

En este sentido, Pibernat citado por Ibáñez (2000, p. 18) sostiene que "con la incorporación del diseño, las empresas se dotan de un instrumento que permite la innovación, el incremento de la calidad de sus productos y una actualización general de la oferta acorde con las necesidades del mercado. A través del diseño, la competitividad de los productos puede mejorarse mediante inversiones razonables". De ahí que el diseño como un factor de competitividad centrado en el consumidor, que aporta soluciones formales, mejora condiciones de uso, eficiencia y funcionalidad, deba ser medido y evaluado considerando sus 3 áreas o campos de actuación: producto, comunicación y entorno (Gorb, 1976, citado por Zurlo, 2003, p. 101) y los niveles de integración (estrategia, política, programa y proyecto) del diseño en las empresas (Lecuona, 2009).

\subsection{Mapa de competitividad en diseño - MCD}

A pesar de la importancia del diseño para la competitividad de las empresas, en la búsqueda de información realizada para la formulación de este proyecto, no se detectaron antecedentes en Colombia orientados a medir el uso del diseño en el proceso de desarrollo de competitividad, que permitan evaluar su integración desde la gestión de la empre- 
sa. Aunque en el país se identificaron estudios de caracterización y diagnóstico empresarial en diseño como "Recomendaciones para la gestión de diseño en las pymes de calzado y marroquinería de Bogotá D.C." (Paredes et al., 2007) y "Estudio de caracterización ocupacional del diseño en la industria colombiana" (UN \& SENA, 2008), estos no abordan particularmente el tema de competitividad y no van dirigidos al sector lácteo.

En el país, se identificó el MCD, creado por la Especialización en Gerencia de Diseño y el Centro de Desarrollo Empresarial de la Cámara de Comercio de Bogotá en 1999. Un instrumento de diagnóstico empresarial en diseño, desarrollado desde el enfoque de competitividad, a partir del Mapa de Competitividad del Banco Interamericano de Desarrollo y el Audit de la Universidad Politécnica de Valencia. Esta herramienta permite evaluar de forma integral los diferentes componentes y procesos de una organización en relación con el diseño. Los resultados de su aplicación aportan información sobre los problemas y las necesidades de diseño en las organizaciones y permiten, en una etapa conclusiva, la formulación de recomendaciones estratégicas a partir de planes de acción tanto de corto, como de mediano y largo plazo. Esta formulación se hace desde un nivel directivo, con prioridad en las categorías que requieren una acción concreta y ejecutable, ya sea para mejorar, construir o cambiar positivamente, o eliminar y corregir los problemas causales de la pérdida de competitividad de la empresa.

Aunque la herramienta permite el autoconocimiento de la empresa y de su situación interna respecto al diseño, no considera formas de establecer la relación de las áreas estudiadas con su estrategia competitiva, aspecto central en lo que se refiere a la medición de la competitividad empresarial, ni tampoco dispone de factores de competitividad asociados que puedan hacer posible identificar el referente en función del cual se hizo la medida. En general, es una metodología más para realizar diagnósticos empresariales desde el diseño, más que para estudiar la competitividad. Adicionalmente, este abordaje metodológico relaciona una serie de factores desde una mirada funcional (planeación, producción, producto, calidad, comercialización, gestión am- biental, recursos humanos en diseño) que son determinantes para reconocer la estructura competitiva de una empresa, pero no hace posible establecer las relaciones que existen entre estos parámetros de medición, ya que son estudiados de manera independiente.

Finalmente, este instrumento se centra en el análisis de variables desde valoraciones de tipo cuantitativo de la empresa, dejando de lado variables cualitativas, que se constituyen en elementos importantes para el estudio de aspectos propios del diseño y la competitividad. Estas circunstancias determinaron la necesidad de la actualización y validación del MCD existente, para mejorar sus carencias metodológicas y así poder disponer evaluar de modo adecuado la competitividad empresarial desde el diseño.

\subsection{Antecedentes de la competitividad en el sector lácteo}

Desde la revisión de las políticas que se han propuesto como marco de competitividad en el país, estudios como la "Agenda prospectiva de investigación y desarrollo tecnológico de la cadena láctea colombiana" del Ministerio de Agricultura y Desarrollo Rural (2007), el "Acuerdo de competitividad de la cadena láctea colombiana" del Consejo Nacional Lácteo (CNL, 2010), y los documentos Conpes 3675 y 3676 (DNP, 2010), señalan la importancia económica y social de la cadena láctea, la caracterizan desde sus aspectos productivos y formulan un diagnóstico estratégico para el desarrollo del sector; de allí puede afirmarse que este es un sector que demanda de innovación en diseño desde la dimensión producto/servicio. Sin embargo, a la fecha no se reconocen antecedentes orientados a determinar la situación competitiva y las perspectivas desde el diseño en las empresas productoras y comercializadoras de productos del sector lácteo en la zona Bogotá Región.

En materia de tendencias en investigación básica y aplicada para cadenas productivas agroindustriales en el país, es posible determinar temáticas estándar centradas en la optimización del sistema productivo, del manejo sanitario y fitosanitario, de la calidad, inocuidad y conservación de insumos y productos, 
de genética, fisiología y reproducción animal, manejo ambiental y sostenibilidad, de transferencia de tecnología, y socio economía, y de mercadeo y desarrollo empresarial, entre otros (Uribe et al., 2011). En particular para las empresas productoras y comercializadoras de productos lácteos son comunes los estudios sectoriales de carácter técnico, productivo, administrativo o financiero, que están relacionados con aspectos de competitividad, prospectiva, vigilancia e innovación tecnológica.

De estos estudios, y a partir de la revisión desarrollada hasta el momento, sobresale por su orientación el documento "Lácteos con valor agregado", enmarcado en la investigación "Los núcleos de conocimiento en las apuestas estratégicas de Bogotá y Cundinamarca y los sistemas sectoriales de innovación" realizada en el 2009 por el grupo Conocimiento, innovación, y competitividad de la Pontificia Universidad Javeriana. Este proyecto identificó los grupos de investigación que han trabajado en temas relacionados con el sector lácteo, con el propósito de "identificar las propuestas (oferta) y las necesidades (demanda) de proyectos de investigación, desarrollo e innovación ( $+\mathrm{D}+\mathrm{i})$, formuladas tanto por grupos de investigación, como por empresas innovadoras, para elaborar productos con alto valor agregado como fuente de competitividad en los mercados internacionales" (Malaver \& Vargas, 2009, p. 1). Su importancia se debe a que destaca "la poca valoración de las actividades de I+D+i desde un enfoque estratégico, la falta de recursos humanos y financieros, la desconfianza hacia los grupos de investigación y hacia el trabajo en conjunto con otras empresas, y el desconocimiento de las dinámicas de la investigación" (Malaver \& Vargas, 2009, p. 39), de lo cual se deduce la necesidad de desarrollar proyectos de investigación que propongan acciones puntuales para transformar los avances en $\mathrm{I}+\mathrm{D}+\mathrm{i}$ en productos o servicios competitivos que contribuyan al desarrollo integral del sector.

Por otra parte, aunque no es posible encontrar una producción sistemática en Colombia que sirva de antecedente del estado del arte de la investigación, el desarrollo tecnológico y la innovación a partir del diseño, se ha podido verificar la existencia, el interés y la labor particularmente de dos grupos de investigación con enfoque en gestión de diseño, interesados en ampliar el marco del conocimiento en esta área, para fortalecer la relación entre el diseño y las pymes específicamente del sector manufacturero del país.

Se trata, en primer lugar, del grupo de investigación en gestión de diseño de la Pontificia Universidad Javeriana creado en el 2005 y con clasificación C en Colciencias que desde la línea de investigación "Gestión de conocimiento de diseño en las empresas", ha desarrollado los proyectos: "Estudio sobre los efectos de la intervención del diseño en las pymes de marroquinería y calzado" (2005-2007), "Misión tecnológica en gestión de diseño a España" (2009), y "Diseño, desarrollo y validación de herramientas de apoyo a la gestión de diseño en las pymes de calzado y marroquinería en Colombia y muebles en España" -HAGEDI- (2009-2012).

También se reconoce al grupo en ingeniería de diseño de la Universidad Eafit, creado en el 2006, que con clasificación $\mathrm{B}$ en Colciencias y desde la línea de investigación en "Gestión e innovación en diseño" ha desarrollado los proyectos: "Construcción de una metodología de diagnóstico y auditoría en procesos de desarrollo de nuevos productos para pymes del sector manufacturero en Colombia" (2007), "Formulación de una metodología de formación y evaluación en empresarismo bajo un modelo de competencias" (2008), y "Herramienta de diagnóstico del proceso de diseño y desarrollo de nuevos productos para pymes de manufactura" (2010).

Adicionalmente es importante referir los dos estudios de caracterización en diseño que ha liderado la Facultad de Artes de la Universidad Nacional de Colombia. El primero se realizó en 2008, por solicitud de la Mesa Sectorial de Diseño del Servicio Nacional de Aprendizaje -SENA- y tuvo por objetivo la identificación y descripción de la situación actual y las tendencias de desarrollo del diseño en la industria colombiana, en los entornos ocupacional, organizacional, tecnológico y formativo (UN \& SENA, 2008). El segundo estudio se llevó a cabo en 2009 por solicitud del Ministerio de Comercio, Industria y Turismo y buscó caracterizar la gestión 
estratégica de diseño en casos exitosos a partir de variables de impacto, mejores prácticas adoptadas, modificaciones en procesos, aspectos comerciales, cadenas de valor y ventajas competitivas identificables y determinación de valor agregado en el producto (UN, 2009).

Estos aportes, aunque significativos para ampliar el conocimiento sobre gestión de diseño en el país, no tienen acercamientos particulares al sector lácteo, por un lado, y por otro están centrados en pymes, particularmente del sector manufacturero.

$\mathrm{Al}$ respecto, conviene resaltar que aunque desde el sector académico se han liderado esfuerzos por comprender el grado de inserción del diseño en el sector empresarial del país -una situación posiblemente heredada del origen académico de esta disciplina en Colombia y del afán por identificar estrategias que la articulen con las necesidades del entorno-, mientras en el sector público no se le de la importancia que se le debe dar a la comprensión del impacto del diseño en las empresas, será difícil que esta disciplina pueda apoyar al progreso económico de la nación.

En lo internacional, los referentes en publicaciones científicas de la cadena productiva láctea, en su orden, son Estados Unidos, Brasil, Irlanda, Reino Unido, Canadá, Turquía, Alemania, Polonia, Dinamarca y Nueva Zelanda. En Estados Unidos, se han realizado proyectos relacionados con el mejoramiento en la producción de leche, en el caso de Brasil se analizan la calidad e inocuidad y en Irlanda se evalúan los efectos y bondades de la leche en la salud y nutrición humanas. "Los líderes de investigación más destacados son Buckley F., Dillon P., y Rath M. de Estados Unidos e Irlanda, que trabajan en The Irish Agriculture and Food Development Authority (TEAGASC), Cornell University, USDA ARS y Swedish University of Agriculture Sciences, respectivamente, en mejoramiento de producción de leche" (Flórez, et al., 2012, p. 128). En este marco es notoria la diversidad de artículos de investigación presentada en publicaciones científicas, con enfoque en desarrollos tecnológicos para el mejoramiento de la producción de leche, subproductos y derivados de la calidad microbiológica, sa- nitaria e inocuidad, y de los efectos y bondades de la leche en la salud y nutrición humana.

Para el sector agroindustrial destacan dos aproximaciones; por una parte los análisis de las bondades de la metodología de Evaluación del Ciclo de Vida del producto -ECV- aplicada a las cadenas globales de mercancías, cuyo enfoque en el análisis de efectos ambientales en los eslabones de las cadenas, introducen una preocupación por el diseño de productos (Díaz \& Hartley, 2006, p. 8); por otra, están los estudios sobre competitividad empresarial desde la teoría de capacidades (Traill, 2000; Hyvönen \& Kola, 1998; Viaene \& Gellynck, 1998; citados por Mamaqui, Meza \& Albisu, 2002), que abren un camino para indagar por estas relaciones, al considerar desde la ECV las relaciones existentes entre desperdicio final y diseño de productos, así como desde la teoría de capacidades empresariales, al considerar los factores intangibles como determinantes del éxito empresarial.

Para el caso colombiano, en lo referente al binomio competitividad - diseño no se identificaron estudios directamente relacionados con el sector lácteo que aborden el diseño desde enfoques operativos o estratégicos. Esta situación plantea la necesidad de enfocar nuevos campos de investigación desde la gestión del diseño para la producción de conocimiento y su posterior transferencia en la generación eficiente de nuevos productos o servicios con valor agregado, que contribuyan al aumento de la competitividad del país en los mercados internacionales.

\subsection{Diseño y factores explicativos del éxito em- presarial}

En tesis de doctorado se encontraron algunas sobre la teoría de capacidades empresariales y el análisis de la competitividad a partir de los factores explicativos del éxito empresarial (Sáinz, 2002) y las posibilidades de generar estrategias competitivas híbridas (Cardona, 2011); a partir de lo que plantean es necesario no solo expresar los ámbitos en los cuales el diseño puede llevarse a cabo y su nivel de integración en los procesos internos de la empresa (Ibáñez, 2000) sino además reconocer el papel que puede desempeñar en el éxito de la estrategia competiti- 
va. Esto implica adentrarse en la comprensión de la teoría de las capacidades empresariales de modo que puedan ser de utilidad para la construcción de un marco de referencia para el ajuste metodológico de la herramienta MCD.

El análisis de los factores empresariales o internos de las empresas en los estudios de competitividad hizo su aparición durante los años noventa con la comprensión de que los factores macroeconómicos y sectoriales no fueron suficientes para explicar las diferencias del éxito competitivo por empresas ubicadas en unos territorios compartidos y pertenecientes al mismo sector productivo.

De acuerdo con la compilación elaborada por Sáinz (2002) la teoría de los recursos y capacidades empresariales, a diferencia del planteamiento de Porter (1991) que fundamenta el éxito empresarial a partir de la influencia del comportamiento del sector en la competitividad de la empresa, se considera que la clave del éxito estratégico reside en la empresa y se plantea que la fundamentación del plan estratégico puede generar e incorporar recursos distintivos en la medida en que las empresas reconozcan la diferenciación que les ofrece su dotación de medios productivos (Trece, Pisano \& Shuen, 1990; Hunt, 1997; citados por Sáinz, 2002, p. 119).

Una empresa obtiene una ventaja competitiva, según Sáinz (2002, p. 119) cuando dispone de una característica particular y relevante para el éxito de su negocio, que la pone en una situación de superioridad con respecto a sus competidores. Por lo tanto, el punto de interés del enfoque de recursos y capacidades da mayor importancia a la eficiencia que al mercado, que se orienta hacia la cara interna de la empresa, al considerar que los recursos y las capacidades de la empresa son el elemento clave para la conformación de su comportamiento estratégico.

A partir de los aportes de economistas como Grant \& Barney citados por Sáinz (2002, p. 119) se describen las cuatro hipótesis en las que se fundamenta la teoría de recursos y capacidades, de la siguiente forma:
- Los recursos de la empresa proporcionan la dirección básica de su estrategia.

- Los recursos constituyen la fuente primaria del beneficio empresarial.

- Las empresas de una industria pueden ser heterogéneas con respecto a los recursos que controlan.

- Los recursos de la empresa pueden no ser perfectamente móviles a través de las empresas por lo que esa heterogeneidad puede ser duradera en el tiempo. Ello posibilita el sostenimiento de las ventajas diferenciales y en consecuencia, de los mayores beneficios obtenidos.

- Los recursos se pueden entender de forma general como cualquier factor o elemento que utiliza la empresa para la obtención de los bienes o servicios que destina a sus clientes. La teoría distingue entre recursos tangibles e intangibles. Los factores tangibles son los recursos materiales de la empresa, ya sean físicos o financieros. Los factores intangibles son los relacionados con el know how y el manejo de la información.

Cuervo (1993, p. 364), Salas (1993, p. 379), Vecino (1997, p. 21) citados por Sáinz (2002), coinciden en definir la existencia de 3 categorías de factores que intervienen en el éxito competitivo de las empresas:

- Factores macroeconómicos, relacionados con el marco económico general.

- Factores sectoriales, que pueden afectar a las empresas en función de la diferente naturaleza de su actividad económica.

- Factores empresariales o internos, que tienen que ver con las características intrínsecas de las empresas, como son sus activos físicos y financieros, el capital humano, los activos intangibles como marca, reputación, know-how, experiencia y tecnología, entre otros. 
La importancia y peso que cada autor le da a los factores citados en el análisis de la competitividad de las empresas varía y es motivo permanente de discusión, así como las agrupaciones y jerarquías. No obstante, para el estudio la definición de los factores internos es fundamental dentro del marco que fundamenta conceptualmente el trabajo de investigación, puesto que se asume que el diseño está relacionado con los factores internos de la empresa, en calidad de variable y desde esta perspectiva la gestión del diseño está íntimamente ligada a la estrategia competitiva de la empresa.

Teniendo en cuenta que no todos los recursos empresariales son igualmente valiosos para los distintos modelos de negocio, fue necesario construir una matriz de factores internos explicativos del éxito empresarial-FEE- en la cual se estableciera su relación con las acciones de gestión de diseño, teniendo en cuenta que el proyecto o plan estratégico de una empresa se constituye a partir del manejo de los recursos tangibles o intangibles, y que el diseño puede ser una herramienta utilizada por la empresa para fortalecer sus factores internos en la perspectiva de lograr una ventaja competitiva permanente.

Los FEE, tanto tangibles como intangibles, relacionados con la gestión del diseño, se presentan en la tabla 1 construida teniendo en cuenta los aportes generados por los resultados de la investigación de Aragón \& Rubio (2005) sobre el análisis de los factores explicativos del éxito empresarial en pymes de Veracruz y los planteamientos de Ibáñez (2000) sobre la incorporación del diseño en las empresas.

La orientación para el desarrollo de la siguiente tabla, en la que se resumen tanto los factores como las variables a indagar en el estudio, es la de facilitar la comprensión de las acciones de diseño desde un marco de gestión corporativa, de modo tal que estas no queden reducidas a acciones aisladas o a procesos administrativamente recomendables o en el peor de los casos, suntuarios.

El diseño de producto emerge como un factor decisivo en toda política de innovación; ya no se le puede tratar dentro del contexto industrial como un acto aislado, desvinculado de las actividades globa- les proyectuales y menos asociarlo exclusivamente a una actividad artística, cultural o lúdica. Como decía el Teymur (s.f., citado por Tresserras, 2006, párr. 22): “(...) las relaciones económicas son la única razón de la actividad de diseño de los objetos que produce y algunos diseñadores esconden esta relación o la reducen a una relación que existe como mal necesario. Considero que el tratamiento efectuado del diseño industrial en la década de 1990 por parte de instituciones y medios de comunicación transmitió una visión de la actividad alejada de la realidad industrial y en consecuencia los empresarios no se identificaron plenamente, de modo que por lo general relativizaron las posibilidades del diseño industrial como factor de innovación".

Por el contrario, desde las relaciones establecidas entre los factores y la gestión de diseño aparece una posibilidad de generar estrategias de diferenciación como parte de los planes estratégicos de las empresas, y desde esta perspectiva se justifica la reorientación del instrumento MCD de modo que se convierta en una herramienta estratégica.

Como se observa en la cuarta columna de la tabla 1 , en acciones de diseño se relacionan todas las actividades que una adecuada gestión de diseño podría desarrollar para fortalecer sus factores internos desde los recursos tangibles como intangibles, de acuerdo con el planteamiento de su estrategia competitiva y su misión empresarial.

\section{Metodología}

A partir del marco conceptual y de las necesidades de ajustes a la herramienta, esta investigación se desarrolló en las siguientes etapas, con un enfoque de carácter exploratorio, utilizó diferentes técnicas para la recolección de datos, como la revisión bibliográfica, el estudio y reformulación de instrumentos y la realización de entrevistas y cuestionarios con expertos y empresas del sector (Ilustración 1).

Esta etapa correspondió a la consulta de documentos sectoriales del Consejo Nacional Lácteo-CNL-, Bancoldex, el Ministerio de Industria Comercio y Turismo, el Departamento Nacional de Planea- 
Tabla 1. Factores internos explicativos del éxito empresarial

\begin{tabular}{|c|c|c|c|}
\hline Categoría & Factores & Descripción Básica & Acciones de Diseño \\
\hline \multirow[t]{2}{*}{$\begin{array}{l}\text { Recursos } \\
\text { Tangibles }\end{array}$} & $\begin{array}{l}\text { Recursos } \\
\text { Financieros }\end{array}$ & $\begin{array}{l}\text { Mantenimiento de buenos estándares financieros a tra- } \\
\text { vés de una adecuada gestión financiera. Planificación a } \\
\text { corto plazo. Sistemas de contabilidad de costos. } \\
\text { Presupuestos anuales. Análisis financieros. Endeuda- } \\
\text { miento. }\end{array}$ & $\begin{array}{l}\text { Rubro para inversión en diseño de nuevos produc- } \\
\text { tos. } \\
\text { Porcentaje del presupuesto. } \\
\text { Medición del retorno de la inversión en diseño. }\end{array}$ \\
\hline & $\begin{array}{l}\text { Recursos } \\
\text { Tecnológicos }\end{array}$ & $\begin{array}{l}\text { Inversiones en tecnología de producto o producción. } \\
\text { Uso de la tecnología adquirida o producida. }\end{array}$ & $\begin{array}{l}\text { Tecnología producida por la empresa. } \\
\text { Tecnología de punta adquirida por la empresa. }\end{array}$ \\
\hline \multirow{7}{*}{$\begin{array}{l}\text { Recursos } \\
\text { Intangibles }\end{array}$} & $\begin{array}{l}\text { Gestión de la } \\
\text { Innovación }\end{array}$ & $\begin{array}{l}\text { Capacidad de la empresa para adaptarse a entornos } \\
\text { dinámicos y complejos. Mecanismos que fomenten in- } \\
\text { novación para responder a los cambios en tecnología y } \\
\text { preferencias de los consumidores. }\end{array}$ & $\begin{array}{l}\text { Frecuencia en la generación de nuevos productos } \\
\text { y servicios. } \\
\text { Frecuencia en cambios sustanciales y mejoras en } \\
\text { la producción y productividad. } \\
\text { Metodologías de diseño y desarrollo de productos } \\
\text { utilizadas por la empresa. } \\
\text { Aporte de los procesos de diseño a la construc- } \\
\text { ción de la cultura organizacional. }\end{array}$ \\
\hline & $\begin{array}{l}\text { Gestión } \\
\text { del Proceso } \\
\text { Creativo }\end{array}$ & $\begin{array}{l}\text { Capacidad de la empresa para generar productos y ser- } \\
\text { vicios. }\end{array}$ & $\begin{array}{l}\text { Metodologías de diseño y desarrollo de productos } \\
\text { utilizadas por la empresa. } \\
\text { Aporte de los procesos de diseño a la construc- } \\
\text { ción de la cultura organizacional. }\end{array}$ \\
\hline & $\begin{array}{l}\text { Gestión del } \\
\text { Conocimiento }\end{array}$ & $\begin{array}{l}\text { Consumo y uso de la información del sector, de la com- } \\
\text { petencia, de los consumidores y del interior de la empre- } \\
\text { sa. Sistemas y tecnologías de la información utilizadas. } \\
\text { Aplicación de la información para la realización de estra- } \\
\text { tegias empresariales. }\end{array}$ & $\begin{array}{l}\text { Sistemas de información análogos o digitales utili- } \\
\text { zados por la empresa. } \\
\text { Reconocimiento del conocimiento existente en la } \\
\text { empresa. } \\
\text { Manejo y flujo de información dentro de la empresa. }\end{array}$ \\
\hline & $\begin{array}{c}\text { Gestión } \\
\text { de Mercados }\end{array}$ & $\begin{array}{l}\text { Capacidades de la empresa para lograr conformidad } \\
\text { entre el conjunto de características y atributos del pro- } \\
\text { ducto o servicio con las necesidades y expectativas de } \\
\text { los consumidores. }\end{array}$ & $\begin{array}{l}\text { Lugar y uso del diseño en la empresa para la crea- } \\
\text { ción de producto o servicios acordes con las ne- } \\
\text { cesidades de los consumidores. } \\
\text { Amplitud y profundidad del portafolio, productos } \\
\text { con alta rotación. } \\
\text { Notoriedad de la marca y atributos del producto } \\
\text { que influyen en el posicionamiento. }\end{array}$ \\
\hline & $\begin{array}{l}\text { Capacidades } \\
\text { Directivas }\end{array}$ & $\begin{array}{l}\text { Características del directivo como capacidad de adapta- } \\
\text { ción a nuevas situaciones, manejo de información, rela- } \\
\text { ción con la creatividad y la innovación en los procesos } \\
\text { de la empresa }\end{array}$ & $\begin{array}{l}\text { Procedimientos y formas de toma de decisiones. } \\
\text { Modelo organizativo de la empresa. } \\
\text { Consistencia de las directrices en las áreas de la } \\
\text { empresa. } \\
\text { Uso de los procesos de diseño en el proceso direc- } \\
\text { tivo de la empresa. } \\
\text { Tipos de relaciones con los eslabones de la ca- } \\
\text { dena. }\end{array}$ \\
\hline & $\begin{array}{l}\text { Gestión } \\
\text { del Talento } \\
\text { Humano }\end{array}$ & $\begin{array}{l}\text { Políticas de gestión y dirección de los trabajadores, que } \\
\text { promuevan la atracción del personal competente, la mo- } \\
\text { tivación y formación del personal que tenga la cualifica- } \\
\text { ción que la empresa necesita }\end{array}$ & $\begin{array}{l}\text { Relaciones de la cultura empresarial y el ambiente } \\
\text { laboral con la innovación y el diseño. }\end{array}$ \\
\hline & $\begin{array}{l}\text { Gestión } \\
\text { Estratégica }\end{array}$ & $\begin{array}{l}\text { Ventaja competitiva. Integración vertical. Identidad cor- } \\
\text { porativa. }\end{array}$ & $\begin{array}{l}\text { Capacidades empresariales que desarrollan para } \\
\text { posicionamiento de la empresa y de las marcas. } \\
\text { Tipos de relaciones con los eslabones de la ca- } \\
\text { dena. } \\
\text { Tipos de empresas y tipos de gestión de diseño. }\end{array}$ \\
\hline
\end{tabular}

Fuente: Elaboración propia. 
ción, así como el rastreo y análisis de información existente sobre competitividad y gestión de diseño de carácter académico y empresarial en Colombia, España y México. Se realizó a través de un proceso de revisión y análisis documental que generó como productos 15 documentos secundarios fichados agrupados en 3 áreas: actualidad del sector lácteo en Colombia, normatividad del sector lácteo en Colombia, y desarrollos de la gestión de diseño en diferentes países. De allí se obtuvo un marco conceptual estructurado que permitió la formulación de hipótesis sobre las relaciones entre la gestión de diseño y la competitividad que puedan aplicarse a las empresas del sector lácteo para la reformulación del MCD.

\subsection{Fase 1: Análisis documental}

La metodología de revisión y análisis documental se determinó en correspondencia con los intereses de la investigación y los referentes conceptuales identificados a partir de tres etapas fundamentales:

i) Planificación de la revisión: Se identificaron unos patrones conceptuales que emergieron de los principales elementos del proyecto de investigación considerando el contexto, los actores, el enfoque investigativo e intereses particulares, permitiendo la selección de las siguientes categorías de análisis que serían utilizadas en el proceso de búsqueda: factores de diseño, competitividad, tecnología agropecuaria, política pública.

También se definieron estrategias de búsqueda orientadas a:

- Identificar publicaciones potencialmente relevantes en textos no electrónicos a partir de una revisión manual de literatura en bibliotecas y en

Ilustración 1. Esquema metodológico

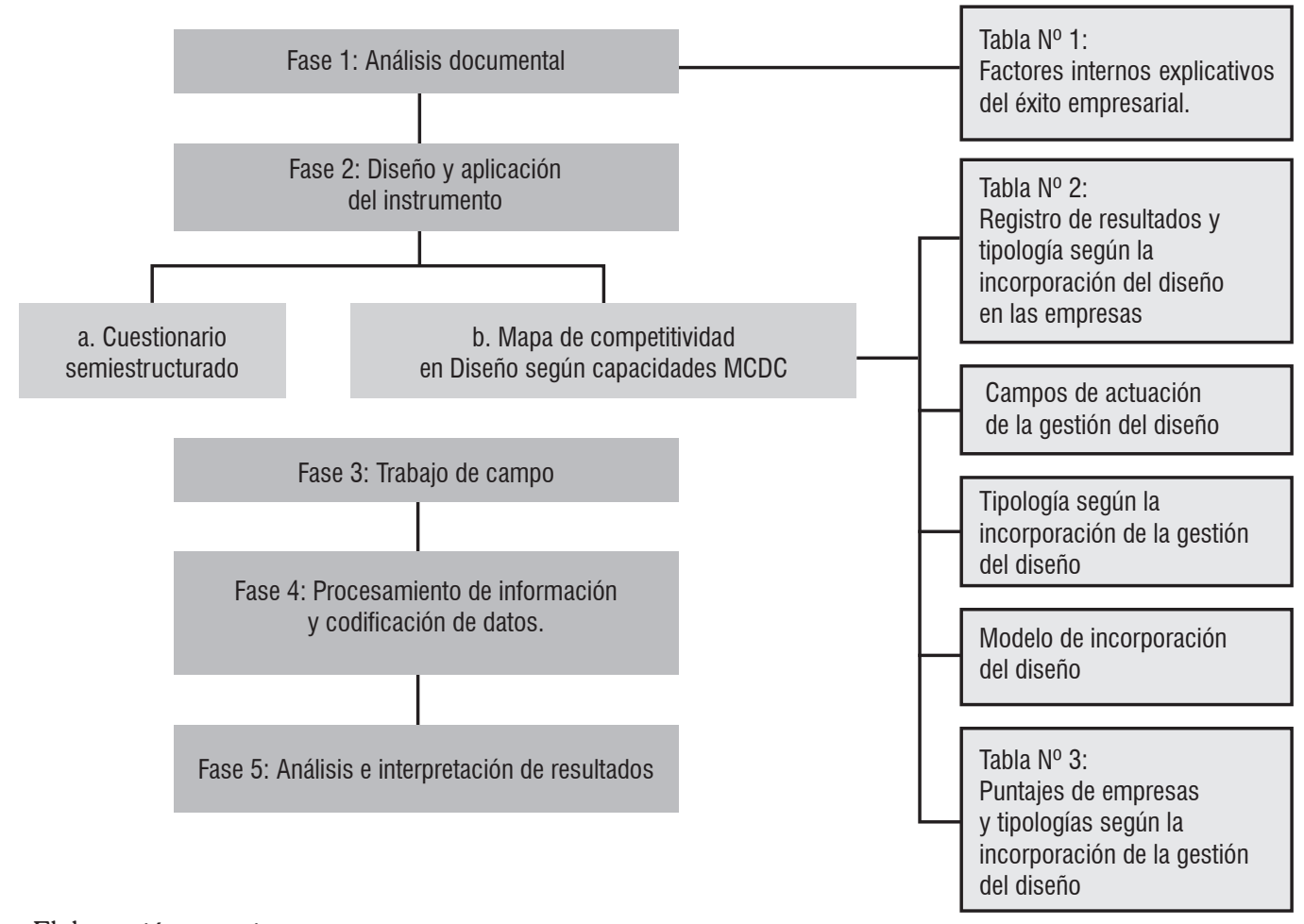

Fuente: Elaboración propia. 
los centros de documentación de entidades de apoyo del sector lácteo.

- Generar una búsqueda por autores a través de Google Scholar y páginas personales de los autores en combinación con los términos definidos.

- Reconocer artículos electrónicos y actas de congresos en bases de datos electrónicas: $R e$ dalyc, Dialnet, Scielo, Agora y Scopus.

- Reconocer indicadores financieros, análisis económico, perspectivas, promedios y proyecciones del sector lácteo en base de datos electrónica: BPR Benchmark.

ii) Desarrollo de la revisión: A partir de los títulos y resúmenes identificados, se realizó una primera selección de 30 documentos en formato electrónico e impreso considerados potencialmente útiles.

Considerando los intereses y los tópicos relevantes para la investigación, se seleccionaron los documentos más idóneos y se elaboraron 15 fichas en el formato de revisión documental que integran los resultados del proceso de recolección de la información.

Para una adecuada gestión de la información, en estas fichas se registraron las ideas de interés de cada uno de los documentos y estudios revisados, así como su localización y referencia bibliográfica.

iii) Síntesis de datos: La estrategia de síntesis de datos permitió el desarrollo del marco conceptual y de la Factores internos explicativos del éxito empresarial referida en la tabla 1.

\subsection{Fase 2: Diseño y aplicación de instrumentos}

Para la formulación de los instrumentos de recolección de información, se utilizó la elaboración conceptual respecto de las relaciones existentes entre los FEE de las empresas consultadas y los procesos de gestión de diseño, en cuanto a ámbitos e incorporación del diseño, resumidos en la tabla 1 denominada Factores internos explicativos del éxito empresarial. De esta forma las acciones de diseño se convirtieron en un área de indagación la cual se fue transformando en categorías de análisis, variables y formas de indagación, tal como se explica a continuación.

En una primera aproximación a la caracterización del sector lácteo en Colombia y en Bogotá Región se elaboró un instrumento cualitativo (cuestionario semiestructurado) con el fin de identificar las perspectivas sectoriales del diseño con expertos vinculados a gremios y entidades del Estado.

En una segunda aproximación a la caracterización del sector lácteo en Colombia y en Bogotá Región se rediseñó el instrumento existente, el cual dio lugar a la creación del MCDC, cuya validación permitió recopilar y analizar los datos de 8 empresas lácteas (micro, pequeñas, medianas y grandes) para reconocer la situación del diseño desde un enfoque estratégico basado en la teoría de capacidades.

i) Cuestionario semiestructurado: Se consideró de gran importancia la realización de entrevistas con expertos, para reconocer necesidades de la gestión de diseño en el sector y plantear acciones conjuntas que aporten a la competitividad de las empresas, debido a que la revisión documental realizada identificó que actualmente el panorama para el sector lácteo se encuentra dominado por planes públicos y de cooperación internacional, dirigidos a fortalecer la producción local frente a las posibles entradas de productos internacionales, como consecuencia de los riesgos y oportunidades que plantean los diferentes tratados de libre comercio suscritos con la Unión Europea, Estados Unidos, México, Chile y Mercosur-que incluye a Argentina, Brasil y Uruguay-, con ganaderías más desarrolladas y mayor conocimiento de segmentación de mercado, innovación y gestión comercial.

En esta fase se dio una aproximación cualitativa con un cuestionario de 5 preguntas abiertas formuladas para su aplicación con 4 expertos clave a nivel sectorial en Colombia y Bogotá Región, seleccionados mediante un muestreo a juicio. El resultado de esta aproximación se obtuvo a través del análisis de con- 
tenido para establecer categorías que llevaran al reconocimiento de las perspectivas sectoriales del diseño con orientación en el desarrollo de conglomerados productivos, la integración de eslabones y la alianza entre la universidad, la industria, el Estado y los gremios. Este acercamiento con entidades del sector facilitó la gestión de contactos con empresas interesadas en hacer parte del estudio.

La información recolectada a partir de esta herramienta, permitió al equipo del estudio la aproximación a la perspectiva desde la cual las entidades públicas que definen políticas para el sector y los gremios comprenden las problemáticas y retos del sector y la cadena láctea.

Desde esta perspectiva la problemática más grande que enfrenta la cadena productiva es la desarticulación de los eslabones que la conforman evidenciándose el trabajo individual especialmente en el eslabón primario, lo cual es coincidente con el análisis expresado en el "Acuerdo de competitividad de la cadena láctea colombiana” (CNL, 2010, p. 20). Por esto los avances más importantes son los derivados de la apuesta por el desarrollo de conglomerados productivos para mejorar la competitividad de las empresas del sector, relacionados con los esfuerzos por la conformación de modelos asociativos que permitan integrar la cadena, las redes empresariales y los sectores conexos y de apoyo, lo que podría permitir mejores niveles de competitividad capaces de liderar el desarrollo de las regiones.

Desde este enfoque los sectores conexos y de apoyo, tales como instituciones gubernamentales, organizaciones gremiales, academia, organismos financieros y de servicios, dan muestra de un interés colaborativo a partir de la propuesta de planes para que las empresas hallen oportunidades de crear valor compartido a través de la re-concepción de los productos y mercados que respondan a las necesidades del mercado, la priorización de temas de investigación e innovación, la caracterización de las zonas o distritos lecheros para focalizar los instrumentos de política pública, el impulso de la reconversión productiva, y los planes de economía solidaria para el desarrollo de la asociatividad local que posibilite mayores sinergias entre ganaderos productores de leche con procesadores y comercializadores.

La mayoría de los expertos reconocen, de acuerdo con el conocimiento de las estrategias y acciones para mejorar la competitividad del sector lácteo, que el diseño no ha sido considerado como factor estratégico de innovación, y su uso se centra en la resolución de problemas de orden productivo particularmente en el primer eslabón de la cadena, u orientado al diseño de envases y empaques o a sistemas de promoción y venta en el eslabón de comercialización.

Entre los expertos se considera que son las empresas grandes las que se apoyan en el diseño para aumentar su competitividad a través de equipos internos conformados por profesionales de diferentes disciplinas (ingenieros de alimentos, profesionales de mercadeo, diseñadores industriales, diseñadores gráficos) encargados del diseño de nuevos productos y de su comunicación con enfoque en el desarrollo de empaques y en el posicionamiento de marca. Sin embargo, no se reconocen antecedentes que permitan determinar que en estas empresas se gestione el diseño desde un enfoque estratégico que permita optimizar la cadena de valor a través del desarrollo de productos o servicios lácteos que respondan a un estudio riguroso de las oportunidades del entorno, las tendencias en los mercados internacionales, la competencia, la identidad de la compañía y las exigencias de los consumidores.

Los expertos entrevistados consideran también que el diseño puede aportar en el eslabón primario con el diseño de herramientas y puestos de trabajo para el mejoramiento de procesos de producción de leche y en el eslabón de comercialización apoyando las estrategias comerciales y de mercadeo. Las oportunidades que se visualizan dan lugar a una noción operativa o instrumental del diseño desconociendo su papel estratégico, a través de la gestión de actividades integrales que permitan incorporar el diseño a la filosofía de empresas y organizaciones

Teniendo en cuenta los aspectos señalados por los expertos del sector, se empezó a reorientar la actualización de la herramienta MCD con la claridad 
de que una herramienta de diagnóstico en gestión de diseño tiene a su vez que ser capaz de relacionar los procesos de diseño con la gestión competitiva de la empresa.

ii) Mapa de competitividad en diseño según capacidades -MCDC-: El MCD es una herramienta creada en 1999, bajo perspectivas pedagógicas; el grupo de investigación se planteó la necesidad de actualizarla dado que a pesar de que ella permitía la generación de autoconocimiento de una empresa y de su situación interna respecto al diseño, no tenía elementos de competitividad asociados que ayudaran a identificar el referente en función del cual se hizo la medida, por lo cual se consideró que era una metodología más propia para realizar diagnósticos empresariales desde el diseño, que para estudiar la competitividad. Para su actualización se partió de la revisión de los elementos conceptuales que le daban sustento, inscritos en la gestión de diseño pero sin contemplar aspectos relacionados con la teoría de capacidades y los factores internos explicativos del éxito empresarial, que ya se identificaron en la primera etapa de este proyecto y fueron probados en investigaciones realizadas sobre competitividad empresarial.

La revisión, modificación y actualización de las categorías de análisis y los contenidos de los enunciados de la herramienta original se modificaron en un $60 \%$, dándoles un enfoque a variables de diseño definidas a partir de elementos conceptuales basados en los factores de competitividad empresarial, así como en los niveles de integración y áreas de actuación del diseño. De esta forma, el nuevo MCDC profundiza en el análisis de las capacidades internas de una empresa desde los factores explicativos internos del éxito empresarial, y está más enfocada en el análisis de los factores que determinan la competitividad desde el diseño, lo que le permite a los empresarios y a la Universidad reconocer las potencialidades que una gestión adecuada de diseño brinda a las empresas para fortalecer su estrategia competitiva.
Como se visualiza en la tabla 2, el MCDC presenta una estructura acorde con una matriz de competitividad por áreas, integrada por las categorías: recursos tangibles, recursos intangibles, recursos humanos y comportamiento estratégico. A su vez cada categoría presenta unos factores de competitividad, descripción básica, variables relacionadas con el diseño, formas de indagación con alternativas de respuesta para selección múltiple y forma de puntuación por pregunta, cuyos resultados permiten ubicar a las empresas consultadas en 5 tipologías (construidas para el efecto: estática, elemental, divergente, funcional y estratégica) según modelo de incorporación, niveles de integración, campo de actuación de la gestión del diseño y descripción de estrategia y acciones, con puntajes relativos a cada nivel y campo.

Las categorías y variables que permitieron establecer las 5 tipologías que identifican los modelos de incorporación del diseño en las empresas, se describen en la tabla de factores de éxito competitivo, la cual es un desarrollo de la matriz FEE planteada en la tabla 1.

El MCDC es un instrumento construido a partir de preguntas cerradas derivadas de las variables a incluir relacionadas con el diseño, con opciones de selección múltiple (en su gran mayoría) para su aplicación a través de entrevistas personales con gerentes de las empresas o personal encargado de los procesos de diseño y desarrollo de productos. Se utilizó un formato de apuntes para consignar las respuestas y los comentarios relacionados con el tema a indagar.

Durante la etapa de revisión, actualización y validación se formularon 8 versiones del instrumento, que se sometieron a revisión y valoración de expertos, entre ellos 4 reconocidos actores del sector y el gremio y por Patricia Paredes López, asesora metodológica y doctora en gestión de diseño. Los actores del sector lácteo con quienes se sometieron a evaluación las diferentes versiones del instrumento para verificar pertinencia y usabilidad fueron: el director ejecutivo de Asoleche, el coordinador del sector lácteo del Programa de Transformación Productiva -PTP- del Ministerio de Comercio, Industria 
Tabla 2. Factores de éxito competitivo del Mapa de Competitividad en Diseño según Capacidades -MCDC-

\begin{tabular}{|c|c|c|c|}
\hline Categorías & Factores & Descripción Básica & $\begin{array}{l}\text { Variables a Incluir } \\
\text { Relacionadas con el Diseño }\end{array}$ \\
\hline \multirow{3}{*}{$\begin{array}{l}\text { Recursos } \\
\text { Tangibles }\end{array}$} & $\begin{array}{l}\text { Gestión de la Identidad } \\
\text { Corporativa }\end{array}$ & $\begin{array}{l}\text { Antigüedad, forma jurídica, distribución del capital } \\
\text { social, tipología de los accionistas y la pertenencia a } \\
\text { un grupo empresarial. }\end{array}$ & $\begin{array}{l}\text { Tipos de empresas. } \\
\text { Tipos de gestión de diseño. }\end{array}$ \\
\hline & Recursos Financieros & $\begin{array}{l}\text { Mantenimiento de buenos estándares financieros a } \\
\text { través de una adecuada gestión financiera. Planifi- } \\
\text { cación a corto plazo. Sistemas de contabilidad de } \\
\text { costos. } \\
\text { Presupuestos anuales. } \\
\text { Análisis financieros. } \\
\text { Endeudamiento. }\end{array}$ & $\begin{array}{l}\text { Rubro para inversión en diseño de nuevos } \\
\text { productos. } \\
\text { Porcentaje del presupuesto. } \\
\text { Medición del retorno de la inversión en } \\
\text { diseño. }\end{array}$ \\
\hline & $\begin{array}{l}\text { Recursos } \\
\text { Tecnológicos }\end{array}$ & $\begin{array}{l}\text { Inversiones en tecnología de producto y/o producción. } \\
\text { Uso de la tecnología adquirida o producida. }\end{array}$ & $\begin{array}{l}\text { Tecnología producida por la empresa. } \\
\text { Tecnología de punta adquirida por la empresa. }\end{array}$ \\
\hline \multirow{7}{*}{$\begin{array}{l}\text { Recursos } \\
\text { Intangibles }\end{array}$} & $\begin{array}{l}\text { Gestión de la } \\
\text { Innovación }\end{array}$ & $\begin{array}{l}\text { Capacidad de la empresa para adaptarse a entornos } \\
\text { dinámicos y complejos. } \\
\text { Mecanismos que fomenten innovación para respon- } \\
\text { der a los cambios en tecnología y preferencias de } \\
\text { los consumidores. }\end{array}$ & $\begin{array}{l}\text { Frecuencia en la generación de nuevos } \\
\text { productos y servicios. } \\
\text { Frecuencia en cambios sustanciales y me- } \\
\text { joras en la producción y productividad. }\end{array}$ \\
\hline & $\begin{array}{l}\text { Gestión del Proceso } \\
\text { Creativo }\end{array}$ & $\begin{array}{l}\text { Capacidad de la empresa para generar productos y } \\
\text { servicios. }\end{array}$ & $\begin{array}{l}\text { Metodologías de diseño y desarrollo de } \\
\text { productos utilizadas por la empresa. } \\
\text { Aporte de los procesos de diseño a la } \\
\text { construcción de la cultura organizacional. }\end{array}$ \\
\hline & Gestión de Mercados & $\begin{array}{l}\text { Capacidades de la empresa para lograr conformidad } \\
\text { entre el conjunto de características y atributos del } \\
\text { producto o servicio con las necesidades y expecta- } \\
\text { tivas de los consumidores. }\end{array}$ & $\begin{array}{l}\text { Lugar y uso del diseño en la empresa para } \\
\text { la creación de producto/servicios acordes } \\
\text { con las necesidades de los consumidores. }\end{array}$ \\
\hline & $\begin{array}{l}\text { Gestión del } \\
\text { Conocimiento }\end{array}$ & $\begin{array}{l}\text { Consumo y uso de la información del sector, de la } \\
\text { competencia, de los consumidores y del interior de } \\
\text { la empresa. } \\
\text { Sistemas y tecnologías de la información utilizadas. } \\
\text { Aplicación de la información para la realización de } \\
\text { estrategias empresariales. }\end{array}$ & $\begin{array}{l}\text { Sistemas de información análogos o digi- } \\
\text { tales utilizados por la empresa. } \\
\text { Reconocimiento del conocimiento existen- } \\
\text { te en la empresa. } \\
\text { Manejo y flujo de información dentro de la } \\
\text { empresa. }\end{array}$ \\
\hline & $\begin{array}{l}\text { Capacidades } \\
\text { Directivas }\end{array}$ & $\begin{array}{l}\text { Características del directivo como capacidad de } \\
\text { adaptación a nuevas situaciones, manejo de infor- } \\
\text { mación, relación con la creatividad y la innovación } \\
\text { en los procesos de la empresa }\end{array}$ & $\begin{array}{l}\text { Procedimientos y formas de toma de de- } \\
\text { cisiones. } \\
\text { Modelo organizativo de la empresa. Con- } \\
\text { sistencia de las directrices en las áreas de } \\
\text { la empresa. } \\
\text { Uso de los procesos de diseño en el pro- } \\
\text { ceso directivo de la empresa. }\end{array}$ \\
\hline & $\begin{array}{l}\text { Gestión del } \\
\text { Talento Humano }\end{array}$ & $\begin{array}{l}\text { Políticas de gestión y dirección de los trabajadores, } \\
\text { que promuevan la atracción del personal competen- } \\
\text { te, la motivación y formación del personal que tenga } \\
\text { la cualificación que la empresa necesita. }\end{array}$ & $\begin{array}{l}\text { Relaciones de la cultura empresarial y el } \\
\text { ambiente laboral con la innovación y el } \\
\text { diseño. }\end{array}$ \\
\hline & Gestión Estratégica & $\begin{array}{l}\text { Portafolio de producto y concentración de los mer- } \\
\text { cados. Ventaja competitiva. } \\
\text { Integración vertical. }\end{array}$ & $\begin{array}{l}\text { Amplitud y profundidad del portafolio, pro- } \\
\text { ductos con alta rotación. Notoriedad de la } \\
\text { marca y atributos del producto que influ- } \\
\text { yen en el posicionamiento. } \\
\text { Tipos de relaciones con los eslabones de } \\
\text { la cadena. }\end{array}$ \\
\hline
\end{tabular}

Fuente: Elaboración propia. 
y Turismo, y Leonardo Castaño Herrera, asesor y consultor del -PTP- del mismo ministerio especializado en diseño. Con la experta asesora en gestión de diseño, se verificó la coherencia y validez interna del instrumento.

Así mismo para la validación y aplicación del instrumento en el sector, se utilizó el muestreo denominado bola de nieve para establecer las empresas posibles de contactar a través de las entidades estatales y gremios consultados y a partir de un muestreo por cuotas se seleccionó un grupo de 8 empresas que permitiera la aplicación de la herramienta en grupos representativos y homogéneos según el tamaño de las empresas así: dos grandes, dos medianas, dos pequeñas y dos microempresas, de modo que la aplicación de la herramienta se probara en empresas de diversas características y su aplicación se pudiese cotejar por pares. Se contó con acceso a los reportes sectoriales actualizados de la base de datos Benchmark (2015) para la consulta de las empresas seleccionadas en el proceso de validación y aplicación del MCDC, y en ella se rastreó información relacionada con los rangos de activos y de empleados que manejan y que se ajustan a la legislación colombiana.
La información que permitió validar el MCDC corresponde a los resultados del registro de datos de las 8 empresas visitadas que se cruzan para su análisis en una matriz que incluye los puntajes obtenidos a través de la aplicación del instrumento por empresa, la clasificación que este puntaje le otorga, la tipología en la cual queda ubicada a partir de la clasificación, la descripción de su tipología según la incorporación del diseño, los ámbitos en los cuales desarrolla sus acciones de diseño, la descripción de sus campos de actuación y el nivel de incorporación de diseño de acuerdo con el análisis de cada uno de los aspectos descritos (tabla 3).

Los campos de actuación y los niveles de integración se establecen a partir de la información suministrada por las empresas para la aplicación del MCDC, contrastada con los ámbitos de la gestión del diseño propuestas por Lecuona (2002) y Best (2007), según los cuales en las empresas el diseño está activo en tres ámbitos: el estratégico, el táctico y el operativo. Dentro del área estratégica se definen las políticas, misiones y agendas generales que debe cumplir el diseño; en el ámbito táctico se de-

Tabla 3. Registro de resultados y tipología según la incorporación del diseño en las empresas

\begin{tabular}{|c|c|}
\hline Empresa & Empresas Consultadas \\
\hline Rango & $\begin{array}{l}\text { Rango en el cual se ubica según tipología: } 0 \text { a 200, } 201 \text { a 400, } 401 \text { a 600, } 601 \text { a } 800 \text { y } 801 \text { a } 1000 \\
\text { puntos }\end{array}$ \\
\hline Puntaje & Puntaje obtenido \\
\hline $\begin{array}{l}\text { Tipología degún la incorporación de la Gestión } \\
\text { del Diseño }\end{array}$ & $\begin{array}{l}\text { Tipología en la cual se ubica según sus características: estática, elemental, divergente, funcional y } \\
\text { estratégica }\end{array}$ \\
\hline $\begin{array}{l}\text { Descripción de Estrategia y Acciones en Ges- } \\
\text { tión de Diseño }\end{array}$ & Descripción de las acciones de diseño según tipologías \\
\hline Ámbitos & $\begin{array}{l}\text { Ámbito en la cual se inscriben las acciones de diseño de la empresa desde abordaje: operativo, } \\
\text { táctico o estratégico }\end{array}$ \\
\hline Campos de Actuación de la Gestión del Diseño & $\begin{array}{l}\text { Campos de actuación en los cuales la empresa desarrolla sus acciones de diseño desde las áreas } \\
\text { de: producto, comunicación y entorno }\end{array}$ \\
\hline Niveles de Integración de la Gestión del Diseño & $\begin{array}{l}\text { Nivel de integración de la gestión del diseño que la empresa ha logrado de acuerdo con el marco } \\
\text { conceptual utilizado, definidos desde: la ausencia de gestión de diseño y los niveles de procesos de } \\
\text { creación, proyectos, programas y filosofía y política }\end{array}$ \\
\hline Modelo De Incorporación del Diseño & $\begin{array}{l}\text { Modelo de incorporación del diseño de acuerdo con el tamaño de la empresa: colaborativo, con } \\
\text { asesorías externas y con equipo internos y asesorías externas }\end{array}$ \\
\hline
\end{tabular}

Fuente: Elaboración propia. 
terminan los equipos, tiempos, presupuesto, procesos y sistemas de las distintas unidades y funciones empresariales relacionadas con el diseño, y en el campo operativo, el diseño se refleja en los productos, servicios y experiencias tangibles, resultados de la implantación de los proyectos y procesos.

De esta forma y a partir de Lecuona (2002) y Best (2007) se reconocen 3 campos de actuación de la gestión del diseño desde los ámbitos operativo, táctico y estratégico:

- Ámbito operativo: la empresa resuelve necesidades básicas relacionadas con producto, $\mathrm{CO}^{-}$ municación o entorno a través de actividades esporádicas de diseño.

- Ámbito táctico: en la empresa coexisten proyectos de diseño en producto, comunicación y entorno con diferentes niveles de organización y duración, sin que estén articulados por la estrategia competitiva de la compañía.

- Ámbito estratégico: el diseño en la empresa está dirigido y coordinado a partir de la estrategia competitiva de la empresa que garantiza la coherencia entre producto, comunicación y entorno.

Los niveles de integración están definidos desde la ausencia de gestión de diseño hasta el nivel de filosofía y política, pasando por los niveles de procesos de creación, proyectos y programas y se articulan con las tipologías de empresas según modelos de incorporación de la gestión del diseño.

De acuerdo con Lecuona (2002) producto, comunicación y entorno son los 3 campos o áreas de actuación en las que se inscriben las actividades de diseño y en las que ha de estar incorporado de forma gradual, considerando las variables estratégicas y recursos de la empresa. El producto hace referencia a la resolución de los aspectos formales, constructivos y de uso del producto, determinando todas sus características, desde su origen hasta aspectos de mercadeo que tienen que ver con su puesta en el mercado. La comunicación comprende funciones que pueden agruparse en diseño de la identidad y diseño de la información. Las actividades a desarrollar pueden ser múltiples: diseño de señalización, diseño de carteles, diseño de empaques y diseño de elementos promocionales, que cubre desde el material publicitario de un anuncio hasta un catálogo o una página web. El entorno integra las actividades de diseño de espacios físicos interiores y exteriores que incluyen entre otros la organización y equipamiento de establecimientos comerciales, ferias, diseño de puntos de venta, colocación del producto, interacción entre espacios y objetos, iluminación del producto y gestión del espacio y de las sensaciones.

El abordaje de estos 3 campos debe desarrollarse paralela $e$ interdisciplinariamente a la estrategia definida para los nuevos productos o servicios y de esta forma lograr proyectar respuestas unificadas y coherentes con la empresa y el mercado.

Asimismo, a partir de los resultados de la aplicación del MCDC y para la identificación de los diferentes modelos de incorporación de la gestión del diseño se definieron las siguientes tipologías de empresas:

- Tipología estática: la empresa no usa el potencial de la gestión del diseño para fortalecer sus factores competitivos internos. A esta tipología corresponde un rango de 0 a 200 puntos, donde las actividades de diseño se resuelven desde un ámbito operativo y hay ausencia de gestión del diseño.

- Tipología elemental: la empresa realiza procesos de creación que no logran fortalecer sus factores de competitividad porque no están articulados a una estrategia, un programa o un proyecto. A esta tipología corresponde un rango de 201 a 400 puntos y un nivel de integración de la gestión del diseño a través de procesos de creación desde un ámbito operativo.

- Tipología divergente: la empresa logra resolver problemas puntuales de competitividad a partir del desarrollo de proyectos de diseño que dan orientación a sus procesos de creación sin que logren afectar de manera permanente la dinámica y orientación estratégica de la empresa. A esta tipología corresponde un rango de 401 
a 600 puntos y un nivel de integración de la gestión del diseño a través de proyectos desde un ámbito táctico.

- Tipología funcional: la empresa logra orientar sus factores internos de competitividad hacia objetivos específicos mediante proyectos de producto, comunicación y entorno aunque no llegan a estar articulados a una estrategia y puedan ser contradictorios entre sí. A esta tipología corresponde un rango de 601 a 800 puntos y un nivel de integración de la gestión del diseño a través de programas desde un ámbito táctico.

- Tipología estratégica: la empresa articula y orienta sus factores internos de competitividad para generar diferenciación en sus productos, comunicación y entorno mediante una estrategia de gestión del diseño. A esta tipología corresponde un rango de 801 a 1000 puntos y un nivel de integración de la gestión del diseño a través de filosofía y política desde un ámbito estratégico.

Cada una de las 8 empresas que hizo parte del proceso de validación se caracterizó de acuerdo con un puntaje relativo en una tipología específica y en un campo de actuación, de acuerdo a la integración de la gestión del diseño en su estrategia competitiva.

A partir de este análisis y aclarando que la gestión del diseño en las empresas debe adaptarse a las particularidades de las diferentes organizaciones, se plantearon los siguientes modelos de incorporación del diseño posibles de acuerdo con la forma como se adquiere el diseño para micro, pequeñas y medianas y grandes empresas, así:

- Modelo colaborativo -modelo de incorporación para empresas microempresas-: en este modelo se vincula el diseño a través de asesorías externas integrales dirigidas a grupos de empresas del mismo sector con necesidades similares de gestión desde los ámbitos de producto, comunicación y entorno.

- Modelo con asesorías externas -modelo de incorporación para empresas pequeñas y me- dianas-: en este modelo la empresa vincula el diseño a través de servicios externos con consultas regulares o puntuales. En este sistema es necesario contar con un interlocutor en la empresa capaz de detectar los proveedores de diseño convenientes y las características y límites del servicio de diseño que se requiere. En este caso no solo se adquiere el diseño para el abordaje en los ámbitos de producto, comunicación y entorno, sino que también se obtienen las habilidades precisas para gestionarlo a través del vínculo con asesores en gestión de diseño y los procesos de formación y especialización del personal interno que esto requiere. Según José María Ibáñez, este modelo puede ser adecuado para la pequeña empresa, $e$ incluso puede ser imprescindible en las primeras etapas de incorporación del diseño a las medianas y grandes empresas sin experiencia (Ibáñez, 2000, p. 354).

- Modelo con equipo interno y asesorías externas -modelo de incorporación para empresas grandes-: en este modelo la empresa cuenta con un departamento interno y asesorías externas tanto para la realización del diseño desde los ámbitos de producto, comunicación y entorno, como para su gestión. Según Ibáñez (2000, p. 354): “(...) atendiendo al momento del desarrollo de un nuevo producto en el que la empresa introduce el diseño entre sus instrumentos de gestión, es posible identificar los siguientes tipos de gestión del diseño: 1) la empresa contrata las ideas o el estilo de un diseñador y su equipo técnico interno desarrolla el nuevo producto o servicio, 2) la empresa desarrolla la ingeniería del producto y contrata servicios externos para adaptar el producto a la imagen de la empresa, 3) la empresa contrata servicios externos de diseño al final del proceso de diseño de un nuevo producto para corregir las insuficiencias producidas en el desarrollo interno del proceso y darle una estética adecuada, 4) la empresa integra algunos especialistas externos de diseño en el equipo interno de la empresa para vitalizar la creatividad de su equipo interno". 


\subsection{Fase 3: Trabajo de campo}

La investigación tomó en cuenta empresas con el siguiente perfil: grandes, medianas, pequeñas y micro ubicadas en Bogotá Región, productoras y comercializadoras del sector lácteo, legalmente constituidas con mínimo 3 años de funcionamiento, procesos productivos artesanales o industriales, al menos un producto derivado lácteo en su portafolio (cremas y mantequillas, quesos, leches azucaradas, helados y postres, leches ácidas y fermentadas), ventas al por mayor y al detal y canales de distribución directos o indirectos.

Se realizaron entrevistas con gerentes o personal encargado de los procesos de diseño y desarrollo de productos de las empresas 8 desde el mes de octubre de 2014 hasta marzo del 2015.

\subsection{Fase 4: Procesamiento de información y codi- ficación de datos}

Para el procesamiento de datos se previó la construcción de una matriz de una sola entrada con categorías de preguntas organizadas de acuerdo con los factores explicativos del éxito empresarial y cuyas opciones de respuesta tenían un valor relacional previamente asignado según la importancia dada a los aspectos vinculados, de acuerdo con los conceptos de la gestión de diseño.

El análisis de la información permitió la verificación de la aplicabilidad de las opciones de respuesta dadas por el cuestionario a las empresas consultadas en contraste con la respuesta obtenida, el ajuste del cuestionario y la replicación de las preguntas. Asimismo se usó la verificación de la coherencia y utilidad de las categorías creadas para la ubicación de las empresas y para la usabilidad de los puntajes otorgados a cada pregunta en caso de que se utilice como herramienta auto diligenciado.

El procesamiento de la información, a partir de la matriz, facilitó un análisis comparativo entre las empresas y la organización de resultados en tablas que sintetizan los datos. Estas matrices consolidan los datos de la aplicación del MCDC por empresas, puntaje, rango, tipología según acciones, ámbitos (operativo, táctico y estratégico), campos de actuación (producto, comunicación y entorno), niveles de integración (estrategia, política, programa y proyecto) de la gestión del diseño.

\subsection{Fase 5: Análisis e interpretación de los resul- tados}

Para el análisis de resultados se utilizó la lectura e interpretación de tablas individuales por empresa con sus respectivos puntajes por factor competitivo interno y de tablas comparativas o matrices para cotejar resultados entre empresas. El análisis de resultados hizo necesario la generación de nuevas matrices temáticas y generales que permitieran realizar análisis comparativos según factores y generales para comparar el uso de los recursos de las empresas de acuerdo con el cuerpo conceptual del estudio, lo cual permitió verificar la posibilidad de realizar indagaciones específicas y hacer visible la aplicabilidad que tendría el instrumento, tanto para las empresas como para el gremio.

A continuación se presentan los principales resultados obtenidos a partir de la aplicación del instrumento en 8 empresas del sector lácteo.

Considerando que para este proyecto la competitividad empresarial es una condición que se da a partir de la combinación de diversos factores internos del éxito competitivo desde su relación con las acciones de gestión de diseño, el instrumento diseñado permite analizar las acciones desarrolladas por cada empresa para fortalecer sus factores competitivos internos desde una perspectiva estratégica del diseño. Asimismo permite establecer el nivel de integración de la gestión del diseño utilizado por la empresa, y reconocer el modelo de incorporación del diseño que la organización está utilizando (Ilustración 2).

Adicionalmente, la validación de la herramienta, permitió reconocer su utilidad para la realización de análisis comparativos de las acciones de diseño desarrolladas por las empresas y agrupadas en cada uno de los FEE desde la perspectiva de la gestión de diseño, de modo que permite no solo catalogar las empresas sino comparar las empresas factor por 


\begin{tabular}{|c|c|c|c|c|c|c|c|}
\hline 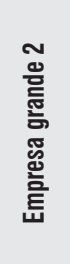 & 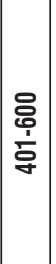 & 岁 & 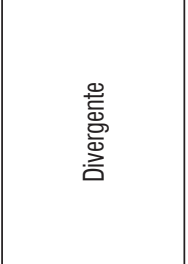 & 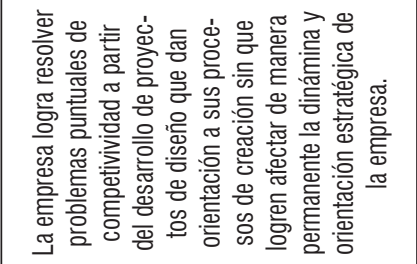 & 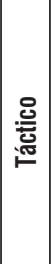 & 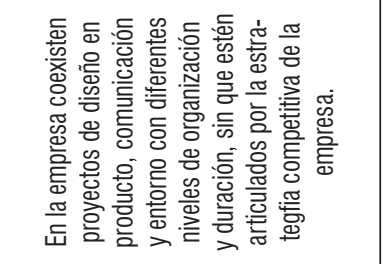 & 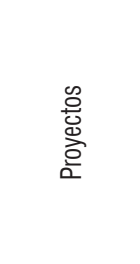 \\
\hline 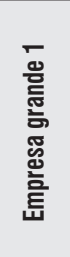 & 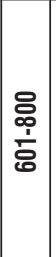 & 웅 & $\begin{array}{l}\overline{\underline{g}} \\
\text { 흘 } \\
\text { 严 }\end{array}$ & 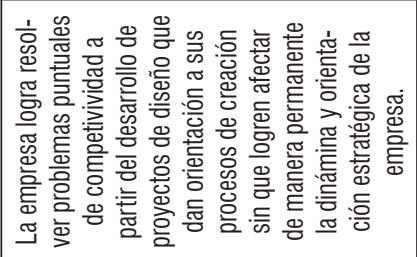 & 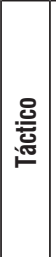 & 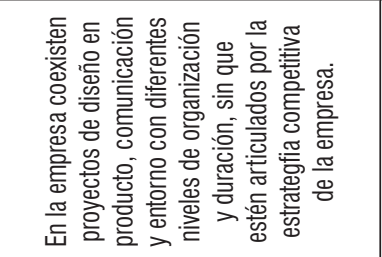 & 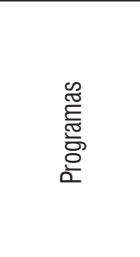 \\
\hline 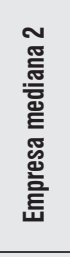 & 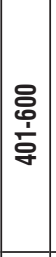 & 釆 & 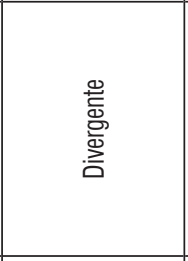 & 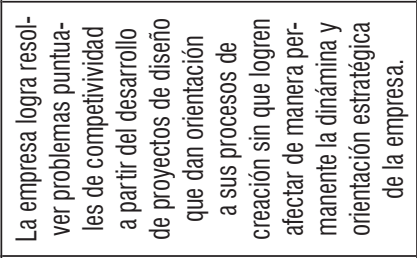 & 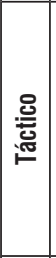 & 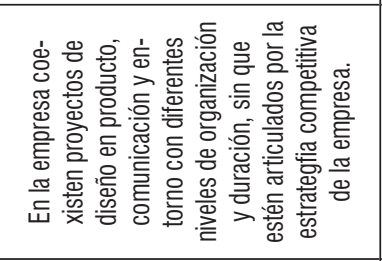 & 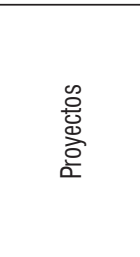 \\
\hline 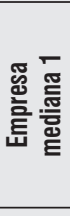 & 容 & $\stackrel{20}{\sim}$ & $\begin{array}{l}\overline{\bar{g}} \\
\text { 焉 } \\
\text { 恶 }\end{array}$ & 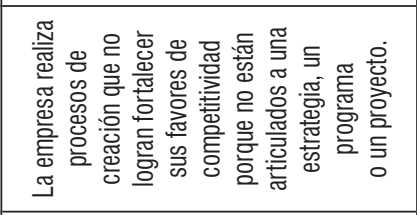 & 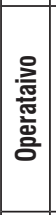 & 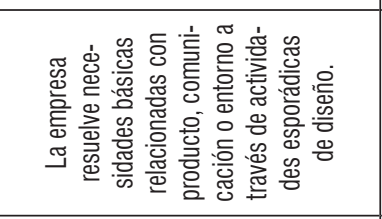 & 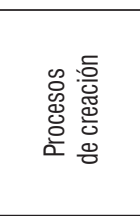 \\
\hline 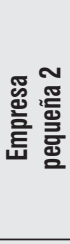 & & 은 & 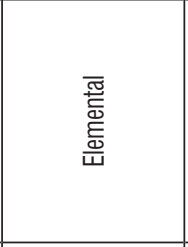 & 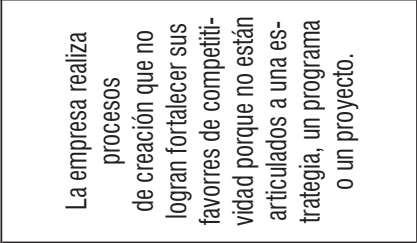 & 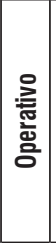 & 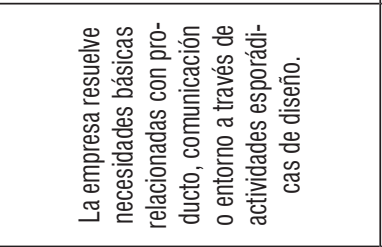 & 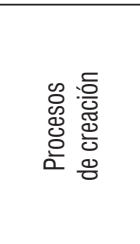 \\
\hline 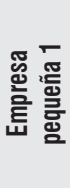 & 空 & 읏 & $\begin{array}{l}\text { 芯 } \\
\text { 密 } \\
\text { 山ै }\end{array}$ & 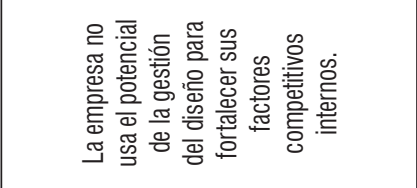 & 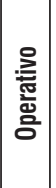 & 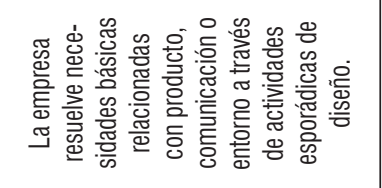 & 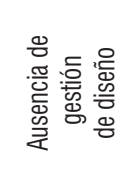 \\
\hline 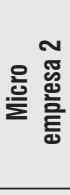 & 亭 & 莡 & 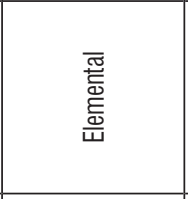 & 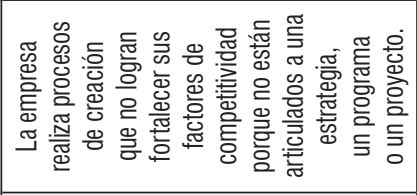 & 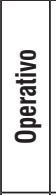 & 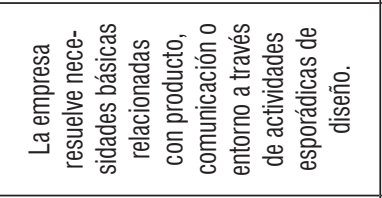 & 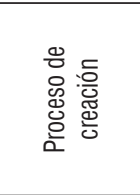 \\
\hline 递惫 & 帘 & 우 & 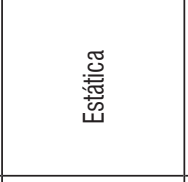 & 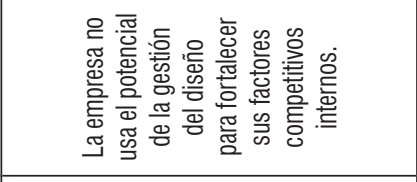 & 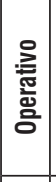 & 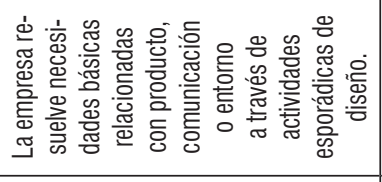 & 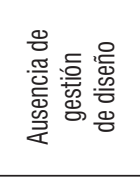 \\
\hline $\begin{array}{l}\text { 巴્心 } \\
\text { 旁 }\end{array}$ & 奇 & 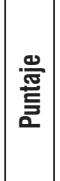 & 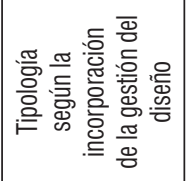 & 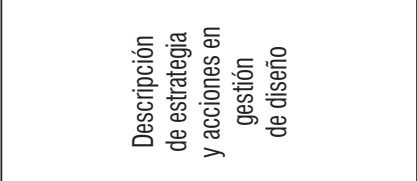 & 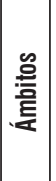 & 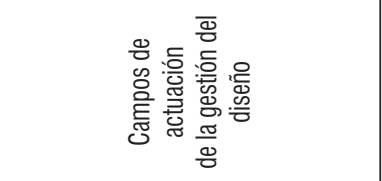 & 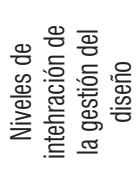 \\
\hline
\end{tabular}

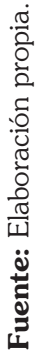


factor; además permite comparar sus estrategias competitivas desde una perspectiva estratégica de diseño, independientemente de sus diferencias en cuanto a tamaño, portafolio y canales de distribución.

A partir de su usabilidad para la realización de análisis transversales la herramienta muestra su eficacia para hacer análisis sectoriales, que se pueden describir en su totalidad o priorizando el factor que se requiera, siempre que la herramienta se aplique en su totalidad.

Para el caso de un análisis como el que se hizo de las 8 empresas con las cuales se validó la herramienta, se obtuvo un resultado individual por empresa y uno colectivo, factor por factor, que muestra la utilidad de realizar un mapa competitivo en diseño de las empresas del sector lácteo. Aunque los resultados obtenidos no son generalizables debido al carácter no probabilístico de la muestra, la tabla 3 presenta los resúmenes por empresa para la realización de un análisis transversal de cada factor.

De acuerdo con los resultados obtenidos en las 8 empresas consultadas es evidente que pese a la importancia estratégica que tiene el diseño como herramienta para potenciar la innovación en el contexto internacional, para favorecer el desarrollo de lácteos con valor agregado, a nivel nacional y regional no hay antecedentes visibles que permitan determinar que en estas empresas se lo considere, de manera explícita, como parte de una estrategia que favorezca su competitividad en el sector. Con una visión tan reducida del diseño es normal que su aplicación se esté dejando de lado o limitando a preocupaciones de tipo productivo, orientadas, en la mayoría de los casos al diseño de envases y empaques o de sistemas de promoción y venta (Ilustración 3); esto explica que no sea abordado desde un planteamiento global, que acompañe todo el recorrido desde la estrategia de una compañía hasta el lanzamiento de un producto, como puede observarse en la siguiente imagen.

Lo anterior permite determinar que el diseño como herramienta para potenciar la innovación es uno de los principales caminos para generar competitividad en el sector lácteo ya que esta depende cada vez más de la creación de ventajas competitivas dinámicas

Ilustración 2. Objetivos de aplicación de la herramienta MCDC

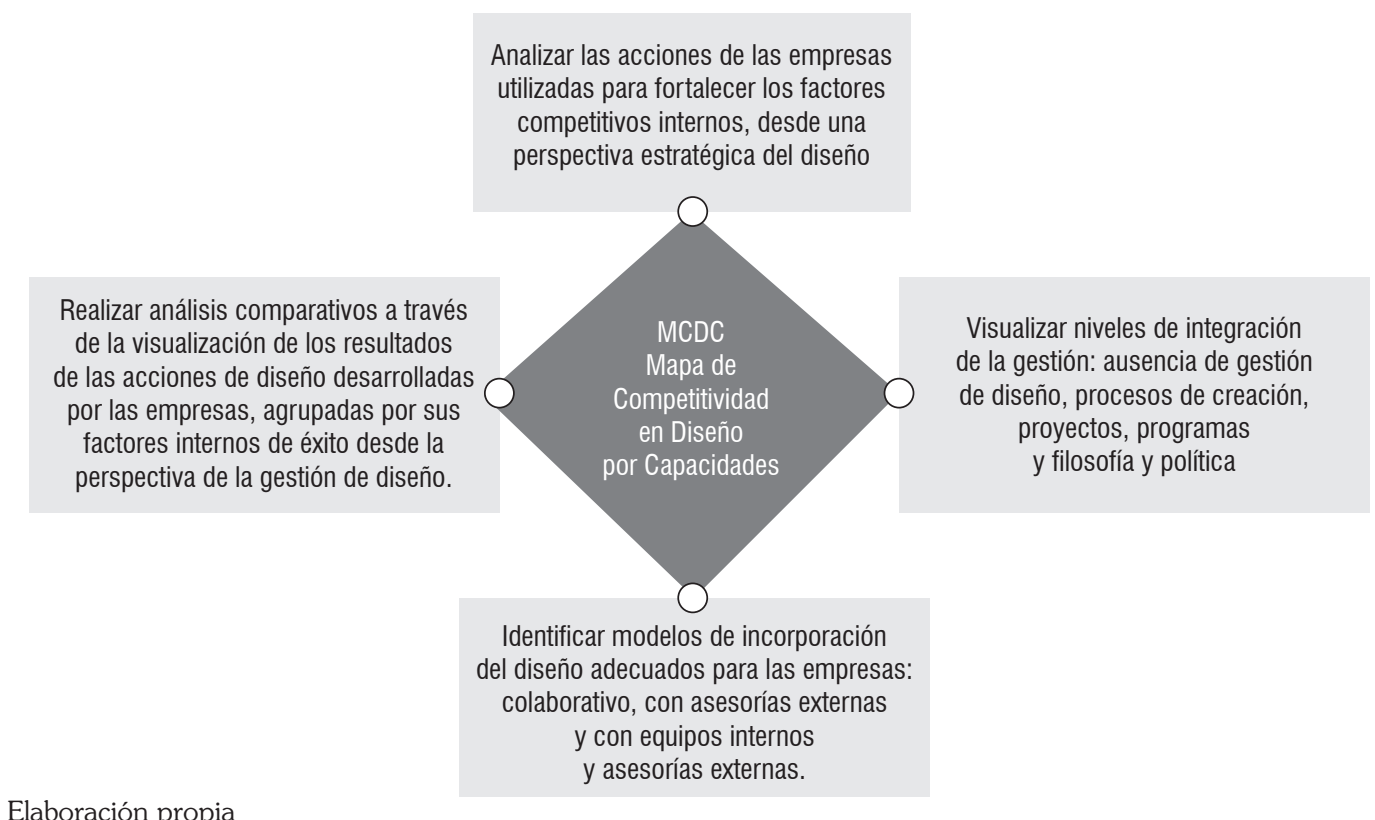

Fuente: Elaboración propia 
soportadas en el conocimiento, la diferenciación y el desarrollo de procesos y productos, y no solamente de la preservación de las ventajas comparativas estáticas basadas en la disponibilidad de recursos naturales, tecnológicos y humanos. De este modo, los factores determinantes de la competitividad dejan de ser exclusivamente los relacionados con el costo de producción, el precio, la calidad, la distribución, la marca, entre otros, para ir abarcando nuevos elementos relacionados con los procesos de investigación y desarrollo, diseño y comercialización.

\section{Conclusiones}

A partir de la consulta de 3 entidades del sector lácteo, así como de la aplicación del Mapa de competitividad de diseño según capacidades -MCDC- en 8 empresas, se pudo establecer la capacidad de este instrumento para determinar la influencia del diseño en sus factores internos de competitividad, lo cual permite validar la caracterización inicial de las empresas del sector a nivel general realizado en el documento de formulación del proyecto, así como plantear perspectivas para la articulación de la gestión del diseño en la estrategia competitiva del sector y de sus empresas.

Ilustración 3. Enfoque del diseño en el sector lácteo

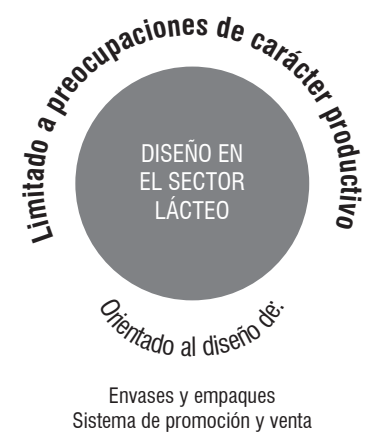

Fuente: Elaboración propia.

A esto se suma, como apuntan los expertos del sector, que los productos de la cadena tienen bajos niveles de diferenciación, apoyados generalmente en las marcas de los bienes finales. En consecuencia terminan comportándose como genéricos sin diferenciación, lo cual incrementa la competencia entre los actores existentes y facilita la entrada de nuevos productores. Actualmente la cadena cuenta con una amplia red de comercialización de productos finales, que garantizan el acceso de los consumidores $y$ existen industrias reconocidas con un claro liderazgo en procesos de mejoramiento de calidad y en diversificación de productos, sin que hayan logrado una potenciación de sus factores competitivos desde el diseño en todos los casos. En este sentido, la investigación en diseño ayudaría a promover la sensibilización hacia actitudes innovadoras a través del reconocimiento de casos de éxito de empresas del sector que adopten el diseño desde un enfoque estratégico.

La aplicación y validación del MCDC ha permitido reorientar su utilización desde un análisis de procesos de diseño hacia el análisis de la relación existente entre los factores de competitividad y la gestión de diseño. Esta aplicación en empresas puede resultar de utilidad para diagnosticar y reconocer áreas de trabajo de diseño que les permita a las organizaciones fortalecer su plan estratégico.

La herramienta MCDC ha probado su aplicación en empresas de diferentes tamaños y complejidad con una frecuencia cero de datos ausentes, por lo cual puede utilizarse en empresas de cualquier tamaño sin necesidad de adaptaciones.

Así mismo, las tipologías utilizadas no dependen de las características específicas de las empresas como tamaño, tipo de organización y complejidad en los procesos, sino del uso de los recursos con los cuales cuenta para desarrollar su plan estratégico. Esta característica permitiría realizar estudios de carácter sectorial que contribuirían en la difícil tarea que el sector lácteo tiene en Colombia de comportarse como una cadena y de fortalecer las condiciones específicas de cada uno de sus eslabones.

Sobre la gestión de diseño en las empresas del sector lácteo consultadas mediante la herramienta, se pudo confirmar que el diseño apoya procesos desde un nivel operativo con enfoque en imagen corporativa, envases y empaques. Por tanto, la diferenciación de los productos entre los competidores no es sustancial y la comunicación del producto y de la 
marca recibe toda la responsabilidad de visibilizar esas diferencias. Una adecuada gestión del diseño, que promueva la articulación del diseño a la estrategia competitiva de la empresa desde un enfoque integral, contribuiría a construir un balance entre los aportes para la generación de atributos en los productos o servicios, entre los procesos de diseño y desarrollo de nuevos productos (lo que fabrica o vende), su comunicación (cómo explica lo que hace) y el entorno (dónde fábrica o vende), a partir de las necesidades y expectativas del mercado.

El 75\% de las empresas valoradas no consultan las necesidades y expectativas de los consumidores para la creación de productos, en su mayoría solo testean la aceptación del producto creado, lo cual les resta una amplia gama de posibilidades de plantearse interrogantes frente al consumo de lácteos. Esto implica que requieren fortalecer la relación entre los procesos de diseño y desarrollo de nuevos productos y la comprensión entre las características y necesidades de los consumidores, así que se hace necesario que el conocimiento de los consumidores promueva actividades de creación de nuevos productos, su comunicación y entorno a partir de la gestión del diseño.

Las relaciones entre diseño y procesos de creación observadas en las empresas que participaron en el estudio, inciden en la debilidad que se observa en cuanto al análisis sistemático de los procesos de diseño de los competidores. Esto no constituye, para la mayoría de las empresas, una fortaleza y por ello se dejan de ver las necesidades no cubiertas en el mercado.

También es notorio que las empresas deben reconocer, acorde con las condiciones cambiantes del entorno y las tendencias de consumo que requieren mecanismos adecuados para rastrear, analizar y detectar oportunidades de diseño y desarrollo de nuevos productos, así como de nueva formas de comunicarlos y posicionarlos en el mercado.

Teniendo en cuenta que a partir de este estudio el Grupo de Investigación en Gerencia de Diseño de la Universidad de Bogotá Jorge Tadeo Lozano cuenta con una herramienta de aplicación eficiente que le permitiría a las empresas del sector lácteo obtener un diagnóstico básico de las necesidades de diseño que tiene su estrategia competitiva actual, y que en caso de ser aplicada en una gran cantidad de empresas del sector permitiría reconocer oportunidades estratégicas en la gestión de la cadena, sería conveniente la generación de alianzas estratégicas entre el sector y la Universidad, desde la lógica de valor compartido que aumente para ambas partes las posibilidades de fortalecer su competitividad desde la gestión del diseño.

Finalmente, los resultados de este trabajo constituyen un punto de partida para aportar conocimiento en el área a nivel nacional, relacionados con la situación competitiva y la incidencia y perspectivas del diseño en el sector lácteo; ayudar a vincular el diseño desde un enfoque estratégico en las empresas de este sector y plantear nuevos proyectos que ayuden a diseñar y desarrollar productos o servicios más adecuados a las necesidades del entorno y el mercado.

\section{Referencias}

Aragón, A. \& Rubio, A. (2005). Factores explicativos del éxito competitivo: el caso de las pymes del Estado de Veracruz. Revista Contaduría y Administración, UNAM, 216, 35-69.

Benchmark (2015). Reportes sectoriales: sector lácteos. Disponible en: http://bck.securities.com/mainview/industryreport?sector $\mathrm{id}=9999010 \& \mathrm{pc}=\mathrm{CO} \& \mathrm{sv}=\mathrm{BCK}$

Best, K. (2007). Design Management. Estrategia, proceso y práctica de la gestión del diseño. Barcelona: Parramón Ediciones.

Bohórquez, N., Buitrago, A., Joya, M., Montaña, X. \& Rivera, H. (2012). Análisis estructural de sectores estratégicos: sector productos lácteos. Documentos de investigación, Facultad de Administración, 135, ISSN: 0124-8219.

Cabrera, A., López, P. \& Ramírez, C. (2011). La competitividad empresarial: un marco conceptual para su estudio. Documentos de investigación, 4. Administración de empresas, Universidad Central. ISBN para PDF: 978-958-26-0267-3

Cámara de Comercio de Bogotá (CCB) (2011). Lácteos con valor agregado en complemento al MEGA. Plan Regional de Competitividad de Bogotá y Cundinamarca 2010-2019. Disponible en: http://www.megagroindustrial.org.co/contenido/contenido.aspx? conID $=3305 \&$ catID $=600$

Cámara de Comercio de Bogotá (CCB) (2013). Informe monitor: creación de la ventaja competitiva para Colombia. Disponible en: http://camara.ccb.org.co/contenido/contenido. aspx? catID $=83 \&$ conID $=1267$

Cardona, R. (2011). Estrategia basada en los recursos y capacidades. Criterios de evaluación y el proceso de desarrollo. Revista Electrónica Fórum doctoral, Universidad EAFIT, 4: 113-147. 
Centro de Diseño de Barcelona (BCD) (2009). El impacto económico del diseño en las empresas de Cataluña. Observatorio Diseño y Empresa Barcelona Centro de Diseño. Disponible en: http://www.bcd.es/site/unitFiles/2521/Impacte $\% 20$ economic_CAST.pdf

Consejo Nacional Lácteo (CNL) (2010). Acuerdo de competitividad de la cadena láctea colombiana. Consejo Nacional Lácteo. Disponible en: http://www.cnl.org.co/index.php?option=com_re mository\&Itemid $=114 \&$ func $=$ startdown\&id $=643$

Cotec (2008). Diseño e innovación, la gestión del diseño en la empresa. Madrid: Fundación Cotec para la Innovación Tecnológica.

DANE (2015). Histórico de exportaciones e importaciones totales, (2008-2013). Disponible en: http://www.dane.gov.co

Díaz, R. \& Hartley, M. (2006). Evaluación del ciclo de vida aplicada en agrocadenas productivas: un instrumento de gestión ambiental para el diseño de políticas. Revista Iberoamericana de Economía Ecológica, 3: 1-15

Departamento Nacional de Planeación (DNP) (2010). Documento CONPES 3675 / 3676. Política Nacional para mejorar la competitividad del sector lácteo Colombiano. Consejo Nacional de Política Económica y Social República de Colombia, Departamento Nacional de Planeación -DNP-. Disponible en: http://www.minagricultura.gov.co/archivos/conpes_3675_ sector_lacteo.pdf.

Duoc UC (1997). Diseño como un sistema integrado de producción y mercado: factores básicos para incrementar la competitividad empresarial de productos manufacturados de cara al siglo XXI. Disponible en: http://www.conicyt.cl/wp-content/themes/fondef/encuentra_proyectos/PROYECTO/97/I/D97I1038.html

Flórez, D., Morales, A., Uribe, C. \& Contreras, C. (2012). Análisis de tendencias en investigación básica para cadenas productivas agroindustriales. Revista Corpoica-Ciencia y Tecnología Agropecuaria, 13(2): 121-135.

Forum (2010). Innovación por diseño en las mipymes. Bogotá: Universidad de la Sabana y el Ministerio de Comercio, Industria y Turismo.

Ibáñez, J. (2000). La gestión del diseño en la empresa. Madrid: McGraw-Hill.

Lecuona, M. (2009). Manual sobre gestión de diseño para empresas que abren nuevos mercados, Barcelona, Barcelona Centro de Diseño. Disponible en: http://www.bcd.es/site/ unitFiles/2122/GD_Manualsobregestióndeldiseño.pdf.

Malaver, F. \& Vargas, M. (2009). Apuesta: lácteos con valor agregado. Los núcleos de conocimiento en las apuestas estratégicas de Bogotá y Cundinamarca y los sistemas sectoriales de innovación. Disponible en: http://www.bogotacundinamarcacompite.org. co/documentos/537_NC_Lacteos.pdf
Mamaqui, X., Meza, L. \& Albisu, L. (2002). Factores que influyen en la competitividad y estrategias de las empresas agroindustriales en Aragón. Revista Agroalimentaria, 14: 69-88.

Ministerio de Agricultura y Desarrollo Rural (2007). Agenda prospectiva de investigación y desarrollo tecnológico de la cadena láctea colombiana. Disponible en: http://www.agronet.gov.co/www/docs_agronet/ 200831311504_Lácteos.pdf

Montaña, J. \& Moll, I. (2008). Éxito empresarial y diseño. Barcelona: Federación Española de Entidades de Promoción del Diseño.

Paredes, P., Salazar, H. \& Bautista, H. (2008). Recomendaciones para la gestión del diseño en las pymes de marroquinería y calzado Bogotá D.C. Bogotá: Javegraf.

Porter, M. (1991). La ventaja competitiva de las naciones. Buenos Aires: Ediciones Javier Vergara.

Sáinz, A. (2002). Análisis de los factores explicativos del éxito empresarial: una aplicación al sector de denominación de origen calificada Rioja. Disponible en: http://dialnet.unirioja. es/descarga/tesis/52.pdf

Tresserras, J. (2006). El diseño industrial como factor de innovación y competitividad. Disponible en: http://tdd.elisava.net/ coleccion/22/serras-i-picas-es

Universidad Nacional de Colombia (UN) \& Servicio Nacional de Aprendizaje (SENA) (2008). Estudio de caracterización ocupacional del diseño en la industria colombiana. Mesa Sectorial de Diseño SENA y Facultad de Artes Universidad Nacional de Colombia, Sede Bogotá. Disponible en: http://www.google. $\mathrm{com} . \mathrm{co} /$ url? $\mathrm{sa}=\mathrm{t} \& \mathrm{rct}=\mathrm{j} \& \mathrm{q}=\&$ \&esrc $=\mathrm{s} \&$ source $=$ web\& $\mathrm{cd}=2 \& \mathrm{ve}$ $\mathrm{d}=0 \mathrm{CCMQFjAB \& url=http} \% 3 \mathrm{~A} \% 2 \mathrm{~F} \% 2 \mathrm{Fwww}$.mipymes.gov. co\%2Fdescargar.php\%3FidFile\%3D4277\&ei=yMIQVZSqJ8y fNrv1AQ\&usg=AFQjCNGeYao_qg25Lr1bKf3hrLUty2cRjw\& sig2=ZXNk9tL9vsP7od8fPolBPg\&bvm=bv.92885102, d.eXY

Universidad Nacional de Colombia (UN) (2009). Estudio estratégico y de caracterización del diseño en las mipymes colombianas. Ministerio de Comercio, Industria y Turismo, y Facultad de Artes Universidad Nacional de Colombia-Sede Bogotá. Disponible en: http://www.mincit.gov.co/publicaciones.php?id=17751.

Uribe, C., Fonseca, S., Bernal, G., Contreras, C. \& Castellanos, O. (2011). Sembrando innovación para la competitividad del sector agropecuario colombiano. Ministerio de Agricultura y Desarrollo Rural, Proyecto transición de la agricultura. Universidad Nacional de Colombia, Grupo de investigación y desarrollo en gestión. Disponible en: http://www.bdigital. unal.edu.co/3567/1/Diagramacion_Libro_MADR_V2.pdf

Zurlo, F. (2003). Del design management al diseño estratégico. Revista Experimenta, 42, 100-105. 